Avaliação prognóstica da doença coronária estável através de um escore composto com dados clínicos e o resultado do teste de esforço

Tese apresentada à Faculdade de Medicina da Universidade de São Paulo para obtenção do título de Doutor em Ciências

Programa de Cardiologia

Orientador: Prof. Dr. Paulo Jorge Moffa 
Avaliação prognóstica da doença coronária estável através de um escore composto com dados clínicos e o resultado do teste de esforço

Tese apresentada à Faculdade de Medicina da Universidade de São Paulo para obtenção do título de Doutor em Ciências

Programa de Cardiologia

Orientador: Prof. Dr. Paulo Jorge Moffa 
Dados Internacionais de Catalogação na Publicação (CIP)

Preparada pela Biblioteca da

Faculdade de Medicina da Universidade de São Paulo

(C) reprodução autorizada pelo autor

Storti, Fernanda Coutinho

Avaliação prognóstica da doença coronária estável através de um escore composto com dados clínicos e o resultado do teste de esforço / Fernanda Coutinho Storti. -- São Paulo, 2011.

Tese(doutorado)--Faculdade de Medicina da Universidade de São Paulo. Programa de Cardiologia.

Orientador: Paulo Jorge Moffa.

Descritores: 1.Teste de esforço 2.Coronariopatia 3.Angina pectoris 4.Prognóstico

USP/FM/DBD-305/11 
Dedico ...

Aos meus pais, Tânía e Gentil, que sempre me estimularam aos estudos e me deram estrutura para que isso acontecesse.

Ao meu marido Daniel que também me incentivava e motivava nas dificuldades dessa longa jornada.

À minha filha Gabriela, um presente que ganhamos durante meu doutorado, com ela aprendi a otimizar ainda maís meu tempo e ver a vida de uma forma bem diferente e muito methor.

Aos meus dois bebês que logo chegarão para completar nossa felicidade. 


\section{AGRADECIMENTOS}

Agradeço ...

Ao meu ilustre orientador Prof. Dr. Paulo Jorge Moffa que me aceitou como sua última orientanda.

Não poderia deixar de agradecer também ao meu grande colaborador e mentor Dr. Augusto Uchida, que me auxiliou em toda essa jornada, sempre disposto a colaborar mais e mais. Muito obrigada.

As secretárias da pós graduação, Neusa, Juliana e Eva, sempre dispostas a orientar e ajudar nas inúmeras dúvidas que nós orientandos temos. 


\section{TESTE DE ESFORÇO \\ Fernanda C Storti}

Com sua praticidade e simplicidade, alcançou o apogeu Porém, muitas vezes confundido ou até mesmo mal interpretado,

Foi desvalorizado...

Com o passar do tempo, dos anos, envelheceu...

Recebeu críticas e foi discriminado,

Pelos jovens, modernos e elitizados...

Mas não esmoreceu...

Com sua maturidade, se consagrou...

Sempre econômico,

Seguro e disponível...

Agora, demonstrando novas características...

Antes encobertas, atualmente reveladas...

E relevantes! 


\section{SUMÁRIO}

Lista de abreviaturas

Lista de siglas

Lista de símbolos

Lista de figuras

Lista de tabelas

Resumo

Summary

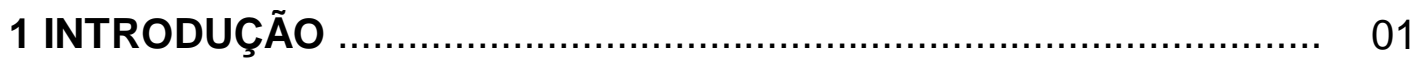

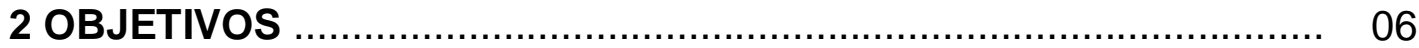

3 MÉTODOS …................................................................. 08

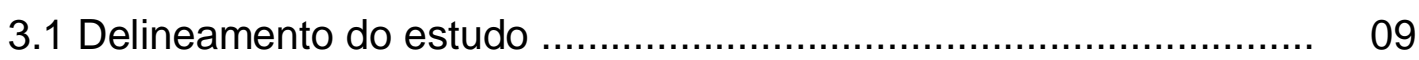

3.2 Grupos de tratamento .................................................... 11

3.3 Desfechos .......................................................................... 14

3.4 Critérios de inclusão ................................................................ 14

3.5 Critérios de exclusão ................................................................. 14

3.6 Definição terminológica .................................................... 15

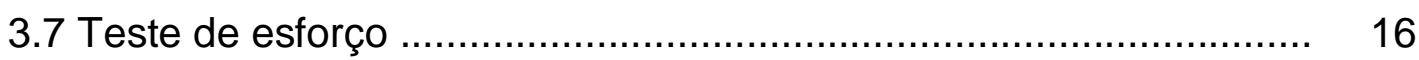

3.8 Escore clínico simplificado ou escore de Hubbard ........................ 21

3.9 Desenvolvimento de escore novo ............................................ 23

3.10 Análise estatística .................................................................. 25

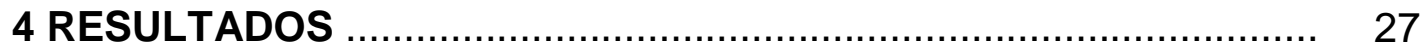

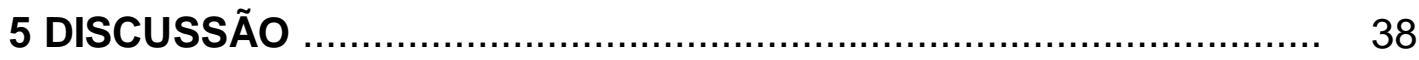

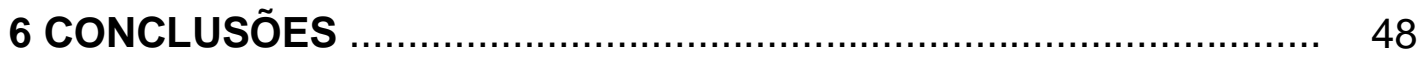


ANEXO - Avaliação prognóstica da doença coronária estável através de uma novo escore

REFERÊNCIAS

\section{APÊNDICES}

Apêndice 1 - Carta de Aprovação da CAPPesq

Apêndice 2 - Termo de Consentimento Livre e Esclarecido 


\section{LISTA DE ABREVIATURAS}

$\begin{array}{ll}\text { ATC } & \text { Angioplastia Transluminal Percutânea } \\ \text { CKMB } & \text { enzima Cretino Kinase-MB } \\ \text { DAC } & \text { Doença Arterial Coronária } \\ \text { FEVE } & \text { Fração de Ejeção do Ventrículo Esquerdo } \\ \text { MASS } & \text { Medicine, Angioplasty or Surgery Study } \\ \text { PAD } & \text { Pressão Arterial Diastólica } \\ \text { PAS } & \text { Pressão Arterial Sistólica } \\ \text { RM } & \text { Cirurgia de Revascularização Miocárdica } \\ \text { TC } & \text { Tratamento Clínico } \\ \text { TE } & \text { Teste de Esforço }\end{array}$




\section{LISTA DE SIGLAS}

CAPPesq Comissão de Ética para Análise de Projetos de Pesquisa

FMUSP Faculdade de Medicina da Universidade de São Paulo

HC Hospital das Clínicas

USP Universidade de São Paulo 


\section{LISTA DE SÍMBOLOS}

\begin{tabular}{|c|c|}
\hline $\mathrm{C}$ & Celsius \\
\hline $\mathrm{dL}$ & decilitro \\
\hline $\mathrm{h}$ & hora \\
\hline $\mathrm{km}$ & quilometro \\
\hline $\mathrm{L}$ & litro \\
\hline $\mathrm{m}$ & metro \\
\hline $\mathrm{mg}$ & miligrama \\
\hline $\min$ & minuto \\
\hline $\mathrm{mL}$ & mililitro \\
\hline $\mathrm{mm}$ & milímetro \\
\hline $\mathrm{mmHg}$ & milímetros de mercúrio \\
\hline $\mathrm{ms}$ & milissegundo \\
\hline $\mathrm{mV}$ & milivolt \\
\hline $\mathrm{s}$ & segundo \\
\hline 0 & grau \\
\hline \pm & mais ou menos \\
\hline$>$ & maior \\
\hline$<$ & menor \\
\hline$\geq$ & maior ou igual \\
\hline$\leq$ & menor ou igual \\
\hline$\%$ & porcento \\
\hline
\end{tabular}




\section{LISTA DE FIGURAS}

Figura 1 Delineamento do estudo

Figura 2 Comparação da taxa de eventos combinados entre os pacientes com escore de Hubbard $<5$ ou $\geq 5$ pontos

Figura 3 Comparação da taxa de eventos combinados entre os pacientes com o novo escore $<6$ ou $\geq 6$ pontos

Figura 4 Comparação entre a taxa de óbito cardiovascular para os pacientes que apresentaram escore de Hubbard com $<5$ pontos e $\geq 5$ pontos

Figura 5 Comparação entre a taxa de óbito cardiovascular para pacientes com escore novo de $<6$ pontos e $\geq 6$ pontos

Figura 6 Análise da curva de sobrevida em relação ao desfecho primário ao comparar os três grupos de tratamento 


\section{LISTA DE TABELAS}

Tabela 1 Protocolo de Bruce ................................................... 17

Tabela 2 Escore de Hubbard …................................................. 22

Tabela 3 Novo escore para estratificação de risco do paciente com DAC estável. O cálculo resulta da somatória dos pontos correspondentes às variáveis listadas

Tabela 4 Distribuição de pacientes dos diferentes grupos de tratamento conforme pontuação dos escores de Hubbard e do novo escore.

Tabela 5 Comparação entre os escores. Distribuição dos pacientes conforme pontuação nos dois escores

Tabela 6 Quantidade de óbitos ao comparar o novo escore e o escore de Hubbard para os três grupos de tratamento, durante os cinco anos de seguimento

Tabela 7 Quantidade de eventos combinados ao comparar o novo escore e o escore de Hubbard, para os diferentes grupos de tratamento durante cinco anos de seguimento 


\section{RESUMO}

Storti FC. Avaliação prognóstica da doença coronária estável através de um escore composto com dados clínicos e o resultado do teste de esforço. [tese]. São Paulo: Faculdade de Medicina, Universidade de São Paulo; 2011. $95 p$.

Introdução. A necessidade de melhorar a acurácia do teste de esforço determinou o desenvolvimento de escores, cuja aplicabilidade já foi amplamente reconhecida.

Objetivo. Avaliação prognóstica do coronariopata estável por meio de um novo escore simplificado ao ser comparado com o escore de Hubbard.

Métodos. Um novo escore foi aplicado em 372 coronariopatas bi ou triarteriais, $71,8 \%$ homens com idade média de 59,5 $\pm 9,07$ anos, randomizados para angioplastia, revascularização cirúrgica e tratamento clínico, com seguimento de cinco anos. O óbito cardiovascular foi o desfecho primário. O infarto do miocárdio não-fatal, e o óbito e re-intervenção formaram o desfecho combinado secundário. O escore baseou-se em uma equação previamente validada, resultante da soma de um ponto para: gênero masculino, história de infarto, angina, diabetes, uso de insulina e ainda um ponto para cada década de vida a partir dos 40 anos. Para o teste positivo foi adicionado um ponto.

Resultados. Ocorreram 36 óbitos (10 no grupo angioplastia, 15 no grupo revascularização e 11 no grupo clínico), $p=0,61$. Observou-se 93 eventos 
combinados: 37 no grupo angioplastia, 23 no grupo revascularização e 33 no grupo clínico $(p=0,058)$. Duzentos e quarenta e sete pacientes apresentaram escore clínico $\geq 5$ pontos e 216 pacientes $\geq 6$ pontos. O valor de corte $\geq 5$ ou $\geq 6$ pontos identificou maior risco, com $p=0,015$ e $p=0,012$, respectivamente. A curva de sobrevida mostrou uma incidência de óbito após a randomização diferente daquela com escore $\geq 6$ pontos $(p=0,07)$, e uma incidência de eventos combinados diferente entre pacientes com escore $<6$ e $\geq 6$ pontos $(p=0,02)$.

Conclusão. O novo escore demonstrou consistência na avaliação prognóstica do coronariopata estável multiarterial.

Descritores: Teste de esforço; coronariopatia; angina pectoris; prognóstico. 


\section{SUMMARY}

Storti FC. Prognostic evaluation of stable coronary disease throughout a score with clinical data and the exercise testing final result. 2011. [thesis]. "São Paulo: Faculdade de Medicina, Universidade de São Paulo"; 2011. 95p.

Introduction. The need to improve the exercise testing accuracy, lead the development of scores, which applicability were already widely recognized. Objective. Prognostic evaluation of stable coronary disease throughout a new simplified score.

Methods. A new score was applied in 372 bi or triarterial coronary patients, $71,8 \%$ men mean age $59,5 \pm 9,07$ years, randomized for percutaneous coronary intervention $(\mathrm{PCl})$, coronary artery bypass graft surgery (CABG) and clinical treatment, with 5 years follow-up. Cardiovascular death was considered the primary outcome. Non-fatal myocardial infarction, death and re-intervention were considered the combined secondary outcome. The score was based on a previously validated equation, resulting from a sum of one point score for: male gender, infarction history, angina, diabetes, use of insulin and one point score for each decade of life after the age of 40 years. Positive exercise testing summed one additional point score.

Results. There were 36 deaths (10 in the PCI group, 15 in the CABG group and 11 in the clinical group), $p=0.61$. There were 93 combined events: 37 in the $\mathrm{PCl}$ group, 23 in CABG group and 33 in the clinical group $(p=0.058)$. Two hundred and forty-seven patients presented a clinical score $\geq 5$ points 
and 216 patients $\geq 6$ points. The cut-off point $\geq 5$ or $\geq 6$ identified an increased risk, $\mathrm{p}=0.015$ and $\mathrm{p}=0.012$, respectively. The survival curve showed a different death incidence after the randomization when the score reached 6 points or more $(p=0.07)$, and a distinct incidence of combined events between the patients with points score $<6$ and $\geq 6(p=0.02)$.

Conclusion. The new score showed to be consistent in the prognostic evaluation of stable multivessel coronary artery disease.

Descriptors: exercise testing, coronary artery disease, angina pectoris, prognosis. 
1 INTRODUÇÃO 


\section{INTRODUÇÃO}

Mesmo com os recentes avanços da medicina tecnológica, implementação de novas técnicas diagnósticas e modernização das existentes, o teste de esforço (TE) convencional com custo baixo, segurança e fácil aplicabilidade ainda é recomendado pela diretriz Americana (Gibbons et al., 2002a) como o primeiro procedimento a ser realizado para avaliação dos pacientes portadores de doença arterial coronária (DAC).

O TE é um exame não-invasivo, que avalia o comportamento do sistema cardiovascular frente ao estresse físico, sob monitorização clínica, eletrocardiográfica e hemodinâmica. A sensibilidade média é de $68 \%$, a especificidade de $77 \%$ e a acurácia de $73 \%$ para diagnóstico de doença coronária (Gibbons et al., 2002b). A sensibilidade é estimada em 40\%, 66\% e $76 \%$ para o uni, bi ou triarterial, respectivamente(Gibbons et al., 2002b).

Com o intuito de melhorar a acurácia e maximizar as informações obtidas no TE, foi desenvolvida uma série de índices e cálculos matemáticos computadorizados auxiliados por métodos estatísticos na forma de escores, que já foram amplamente validados pela literatura científica (Morise, Jalise, 2003; Froelicher et al., 2002; Raxwal et al., 2001; Ashley et al., 2000; Do et al., 1997; Morise et al., 1992; Mark et al., 1987; Diamond, Forrester, 1979;). Ressalta-se que é fundamental observar em qual população o escore foi aplicado, pois quando originado em populações específicas não pode ser adotado de forma genérica. Por exemplo, quando validado em 
coronariopatas, não pode ser aplicado rotineiramente na população em geral.

De forma genérica, a aplicação de escores na abordagem da DAC, melhora a acurácia diagnóstica, auxilia na estimativa prognóstica e elimina vícios de interpretação do teste de esforço (Richardson et al., 1999).

Por meio dos escores pode-se fazer uma avaliação da DAC de forma, no mínimo, tão eficaz quanto ao aplicar exames mais caros e sofisticados e, apesar de não poderem substituir o julgamento do clínico, possuem consistência e confiabilidade reconhecidas por um número crescente de estudos (Froelicher et al., 2002; Ashley et al., 2000).

Atualmente, existem inúmeros escores que podem ser didaticamente classificados em pré-teste ou pós-teste. Ao considerar que se trata de um escore pré-teste, apenas as variáveis clínicas são analisadas, ao incorporar também parâmetros do TE define-se um escore pós-teste (Morise et al., 1992).

Dentre os escores pré-teste mais reconhecidos pode-se citar: Morise e Jalisi (2003), Froelicher et al. (2002) Hubbard et al. (1992) e Diamond e Forrester (1979), entre outros. A análise probabilística preliminar é recomendada rotineiramente pela mais recente diretriz americana (Gibbons et al, 2002a) sobre o TE.

Entre os escores pós-teste principais cita-se: escore de Duke - Mark et al. (1987); escore de Raxwal - Raxwal et al. (2001); escore do Veterans Affairs Medical Center (VAMC) - Morrow et al. (1993); escore de Froelicher Froelicher et al. (2002); escore de Morise - Morise e Jalisi (2003), Do et al. 
(1997); escore de Detrano - Morise et al. (1992), Detrano et al. (1992); escore de Atenas - Lu (1993); escore GISSI 2 - Villella et al. (2003); escore de Koide - Koide et al. (2001); escore de Hollenberg - Hollenberg et al. (1980).

Outra forma de classificação dos escores considera o aspecto da equação complexa ou simplificada. Escores baseados em equações multivariadas possuem fórmulas complexas e trabalhosas que são realizadas por sistemas computadorizados, com ponderação de dados e regressão logística. Dessas equações derivam escores simplificados cujos cálculos são realizados por meio de simples somatória de pontos.

Escores também são categorizados quanto ao cunho diagnóstico ou prognóstico. Escores diagnósticos são estruturados visando a estimativa de probabilidade de DAC, podendo ter caráter prognóstico quando é feita a estimativa de doença grave (padrão triarterial ou lesão de tronco de coronária esquerda). Já os escores prognósticos são idealizados para estratificação de risco, principalmente, de óbito cardiovascular ou infarto não-fatal.

O escore prognóstico mais utilizado, de acordo com a literatura, é o de Duke (Mark et al.,1991), e embora seja amplamente validado, não classifica adequadamente assintomáticos, idosos, pacientes no pósrevascularização do miocárdio e no pós-infarto do miocárdio recente. Além disso, é composto exclusivamente por dados do TE, não incluindo variáveis clínicas; seus resultados não são expressos por valores claros e sua classificação em categorias de risco é complexa e de difícil memorização, 
além de não apresentar correspondência direta com escalas de probabilidade de doença.

Um escore clínico simplificado foi idealizado por Hubbard et al. (1992) com intuito diagnóstico, e é posteriormente validado por Ho et al. (2002) para análise prognóstica de DAC. Contudo, tal escore não inclui uma prova documental de isquemia miocárdica em sua composição, dado que impacta no prognóstico do portador de coronariopatia.

Visando propiciar uma orientação mais completa e objetiva à estratificação de risco do coronariopata estável, é proposto um novo escore pós-teste, que inclui o resultado do TE aos parâmetros do escore de Hubbard et al., (1992). 
2 OBJETIVO 


\section{OBJETIVO}

Avaliação prognóstica do coronariopata estável multiarterial por meio de um novo escore simplificado, composto por dados clínicos e o resultado do teste de esforço. Este novo escore é comparado com um escore previamente validado na mesma população, o escore de Hubbard. 
3 MÉTODOS 


\section{MÉTODOS}

Os dados deste estudo foram coletados por meio de uma análise retrospectiva em pesquisa que foi realizada de forma prospectiva na qual foram avaliados, em série, coronariopatas durante cinco anos incluídos no estudo Medicine, Angioplasty or Surgery Study (MASS-II) (Soares et al., 2006).

O objetivo do estudo MASS foi avaliar, de forma randômica, a abordagem terapêutica de portadores de doença coronária estável multiarterial, em uma única instituição. O modelo do estudo, critérios de seleção e procedimento de randomização foram previamente publicados (Hueb et al., 1995). O estudo foi aprovado pela Comissão de Ética para Análise de Projetos de Pesquisa (CAPPesq) do Hospital das Clínicas (HC) da Faculdade de Medicina da Universidade de São Paulo (FMUSP) (Apêndice 1) e todos os pacientes assinaram o Termo de Consentimento Livre e Esclarecido (Apêndice 2).

\subsection{Delineamento do estudo}

A Figura 1 ilustra o delineamento do estudo no qual foram selecionados, inicialmente, 611 pacientes e a amostra final resultou em 372 pacientes, que foram, então, randomizados para três tipos de tratamento: 
tratamento clínico (TC), angioplastia transluminal coronária (ATC) e revascularização miocárdica $(\mathrm{RM})$. O tempo total de seguimento foi de cinco anos.

Os pacientes que não foram incluídos foram aqueles que apresentavam alterações no eletrocardiograma de repouso, limitantes para documentação de isquemia, os que não atingiram a frequência cardíaca submáxima e outros que não realizaram o exame por motivos sociais. Todos os pacientes apresentavam confirmação angiográfica de coronariopatia bi ou triarterial com função ventricular esquerda preservada.

O delineamento do estudo permitiu aos pacientes uma translocação entre os diversos grupos de tratamento, baseados na ocorrência de sintomas, em qualquer época durante o estudo.

Os pacientes que apresentassem angina instável e que foram selecionados inicialmente para o grupo tratamento clínico, poderiam migrar para o grupo ATC ou RM, conforme a necessidade. Aqueles pacientes com angina instável ou infarto agudo do miocárdio que foram alocados inicialmente para o grupo ATC poderiam receber intervenção cirúrgica ou clínica. Os pacientes que se submeteram a um tratamento cirúrgico também poderiam ser considerados para tratamento clínico, e no caso de uma ocorrência de infarto agudo do miocárdio ou angina instável, seriam encaminhados para angioplastia, e na presença de estenose no local da anastomose ou o aparecimento de uma nova lesão, também seriam submetidos à ATC.

A proporção da amostra estudada foi, destarte, composta por 267 
homens $(71,8 \%)$ e 105 mulheres $(28,2 \%)$, com idade média de $59,5 \pm 9,07$ anos, todos homogeneizados quanto aos três tipos de tratamento: angioplastia transluminal coronária $34,4 \%$, cirurgia de revascularização miocárdica $34,9 \%$ e tratamento clínico $30,6 \%$.

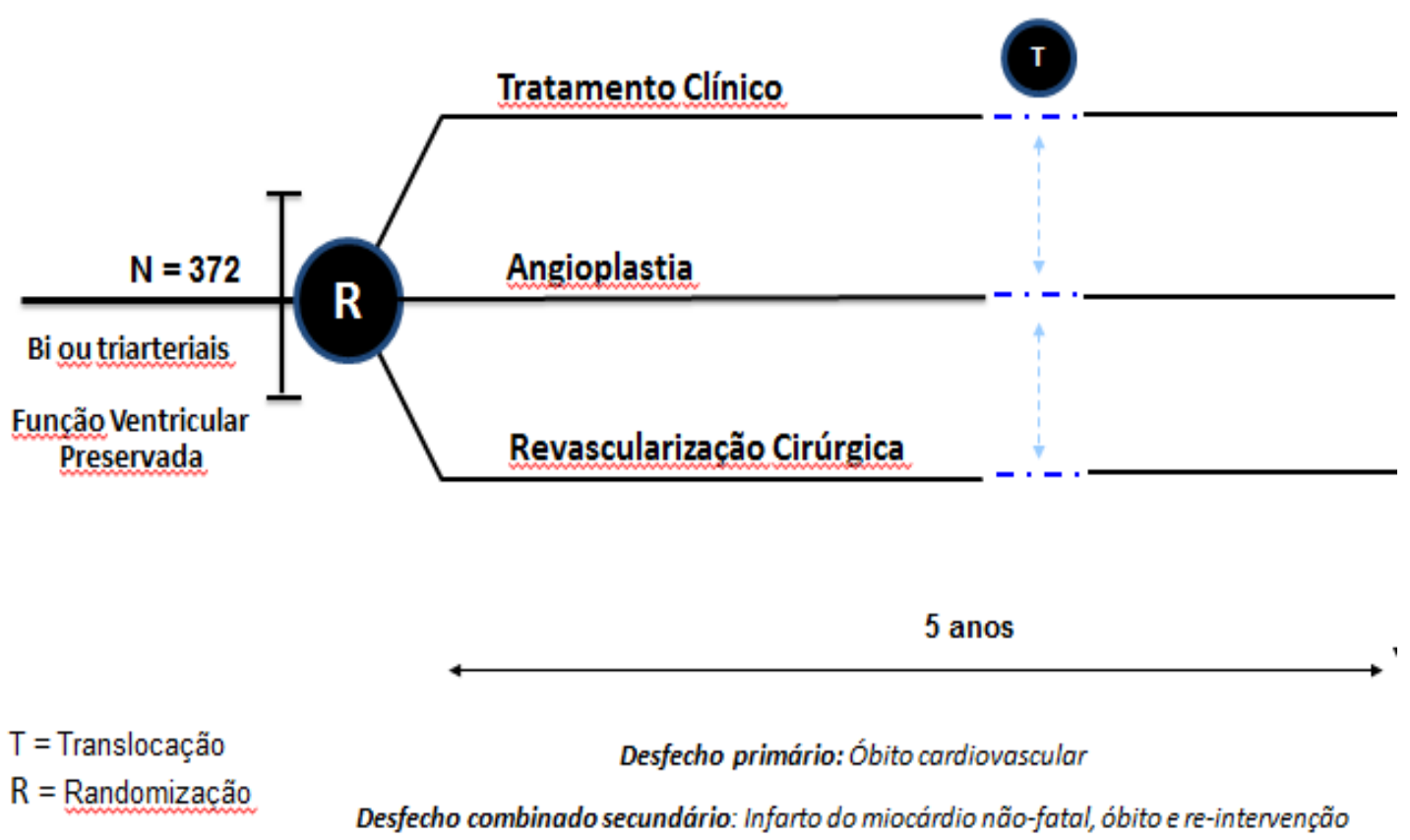

Figura 1. Delineamento do estudo

\subsection{Grupos de tratamento}

Grupo TC. Os pacientes alocados para o tratamento clínico receberam drogas para prevenção e alívio dos sintomas de angina, 
incluindo nitratos, antagonistas de cálcio, betabloqueadores e agentes anti-agregantes plaquetários.

Grupo ATC. O procedimento para a realização da ATC seguiu a técnica convencional (Farb et al., 1990). Todos os pacientes receberam $100 \mathrm{mg}$ de aspirina e bloqueadores de canais de cálcio. Durante o período pré-procedimento, foram administradas $10.000 \mathrm{U}$ de heparina intravenosa e nitroglicerina intra-arterial, intravenosa ou ambas, se necessário.

O dispositivo selecionado foi colocado na descrição do operador e foram incluídos: stents, excimer laser, aterectomia direcional, rotablator e angioplastia com balão. $\mathrm{O}$ cardiologista intervencionista foi estimulado a tratar todas as artérias que provavelmente contribuíam para a isquemia e/ou apresentavam lesão $\geq 70 \%$ de diâmetro da estenose.

A ATC foi realizada conforme o protocolo padrão, que incluiu administração de aspirina antes do procedimento, conforme tratamento preconizado na época do estudo. A dilatação do vaso portador de lesão obstrutiva foi considerada com sucesso se o diâmetro residual do lúmen fosse inferior a $50 \%$. Os pacientes que receberam implante de stent foram mantidos com ticlopidina com dose de $250 \mathrm{mg}$ duas vezes ao dia, diariamente por um mês, além de aspirina com dose diária de $200 \mathrm{mg}$, mantida por tempo indeterminado.

Foram realizadas cinecoronariografias de forma seriada aos seis meses, dois anos e cinco anos após o procedimento; em caso de evento 
isquêmico em qualquer época era indicada nova cinecoronariografia e em casos de reestenose, uma nova angioplastia era realizada.

Grupo RM. Para pacientes deste grupo, o cirurgião cardiovascular foi estimulado a intervir em todas as artérias estenóticas viáveis com a tentativa de realizar revascularização completa. O uso da artéria mamária interna esquerda foi fortemente aconselhado para anastomose com a artéria descendente anterior em todos os pacientes. A circulação extracorpórea foi usada de acordo com a técnica convencional, com uma perfusão de 2,0 a 2,4L/min/ $/ \mathrm{m}^{2}$ e hipotermia sistêmica leve, de $34^{\circ} \mathrm{C}$ a $35^{\circ} \mathrm{C}$.

Todos os pacientes foram clinicamente acompanhados em ambulatório após a revascularização. Não houve diferença no padrão de tratamento medicamentoso entre os três grupos. Todos receberam aspirina por tempo indeterminado. Nitrato, inibidores da enzima de conversão da angiotensina e betabloqueadores foram administrados com o objetivo de manter os pacientes livres da angina pectoris. Foram prescritas estatinas associadas à orientação de dieta hipolipêmica com o objetivo de deixar a lipoproteína de baixa densidade do colesterol $<100 \mathrm{mg} / \mathrm{dL}$. Drogas antihipertensivas foram administradas conforme a necessidade e o julgamento do médico. Os diabéticos foram tratados com sulfoniluréias, insulina e metformina.

Após os cinco anos de seguimento, todos os pacientes dos três grupos de tratamento submeteram-se a uma cinecoronariografia. 


\subsection{Desfechos}

O desfecho primário considerado foi exclusivamente o óbito de natureza cardiovascular, incluindo essencialmente os pacientes com confirmação do diagnóstico de infarto agudo do miocárdio fatal.

O desfecho secundário considerado foi o resultado da combinação dos eventos seguintes: infarto do miocárdio não-fatal, óbito de natureza nãocardiovascular e necessidade de nova angioplastia transluminal coronária ou de nova revascularização cirúrgica do miocárdio.

\subsection{Critérios de inclusão}

Os critérios de inclusão foram:

1. Angina estável;

2. Fração de ejeção do ventrículo esquerdo (FEVE) igual ou superior a $50 \%$, avaliada pelo ecodopplercardiograma transtorácico;

3. Confirmação angiográfica de DAC bi- ou triarterial, com documentação de obstrução luminal de pelo menos $70 \%$, considerando-se somente ramos coronários principais.

\subsection{Critérios de exclusão}

Os critérios de exclusão foram: 
1. Valvopatias de grau moderado a severo;

2. Aneurisma do ventrículo esquerdo;

3. Disfunção ventricular esquerda;

4. Acidente vascular encefálico prévio;

5. Limitação de análise morfológica para definição de isquemia miocárdica no TE: síndrome de pré-excitação ventricular, bloqueio de ramo esquerdo além de outros distúrbios da condução intraventricular, sobrecarga ventricular esquerda, estimulação cardíaca artificial, fibrilação atrial, etc;

6. Incapacidade física de qualquer natureza.

\subsection{Definição terminológica}

Angina estável. A dor anginosa foi classificada conforme sua intensidade variando de I a IV, como definida pela Sociedade Cardiovascular Canadense (Campeau, 1976). Classificação da angina: Classe I indica dor torácica desencadeada por atividade física prolongada ou alto nível de estresse. Classe II, dor torácica desencadeada por nível médio de estresse ou esforço. Classe III dor torácica desencadeada por esforços mínimos. Classe IV caracterizada por dor torácica em qualquer nível de esforço ou até mesmo em repouso.

Angina Instável. Definida como dor torácica em repouso acompanhada de alterações eletrocardiográficas transitórias e discreta elevação da enzima cretino Kinase-MB (CKMB). 
Infarto agudo do miocárdio. Definido quando se notava a presença de ondas Q em pelo menos duas derivações contíguas no eletrocardiograma, com elevação mínima da enzima CKMB de três vezes o valor normal.

Sucesso inicial da ATC. Definido como a redução residual de pelo menos $50 \%$ da estenose, com melhora clínica e sem infarto do miocárdio durante a hospitalização.

Reestenose. Definida como a presença de $50 \%$ de estenose no local onde a dilatação inicial foi alcançada com sucesso.

Sucesso cirúrgico. Definido como sobrevida hospitalar sem infarto do miocárdio nos pacientes originalmente alocados para o tratamento cirúrgico.

Diabetes mellitus. Definido por presença de glicemia de jejum $\geq 126 \mathrm{mg} / \mathrm{dL}$ em pelo menos duas ocasiões distintas. Também foram considerados diabéticos, os pacientes com diagnóstico prévio em uso de medicação específica.

\subsection{Teste de esforço}

Todos os testes de esforço foram realizados em esteira rolante Fukuda Denshi STAR ML-8000, com 15 derivações simultâneas: 12 derivações clássicas do sistema Mason-likar e três derivações do sistema ortogonal de Frank. 
O protocolo de Bruce (1956) foi adotado para todos os exames de TE. É o mais amplamente utilizado na prática clínica, e visa aumentos progressivos da velocidade e da inclinação, como mostra a Tabela 1.

Tabela 1. Protocolo de Bruce.

\begin{tabular}{c|cc|c|c|c|c}
\hline \hline \multirow{2}{*}{ Estágio } & \multicolumn{2}{|c|}{$\begin{array}{c}\text { Velocidade da } \\
\text { esteira }\end{array}$} & $\begin{array}{c}\text { Inclinação } \\
\text { da esteira* }\end{array}$ & Tempo & VO $_{2}$ & MET \\
\cline { 2 - 7 } & $(\mathrm{km} / \mathrm{h})$ & $(\mathrm{M} / \mathrm{h})$ & $(\%)$ & $(\mathrm{min})$ & $\left(\mathrm{mL} \cdot \mathrm{kg}^{-1} \cdot \mathrm{min}^{-1}\right)$ & $\left(\mathrm{mL} \cdot \mathrm{kg}^{-1} \cdot \mathrm{min}^{-1}\right)$ \\
\hline $\mathbf{1}$ & 2,4 & 1,7 & 10 & 3 & 17,0 & 5,5 \\
$\mathbf{2}$ & 4,0 & 2,5 & 12 & 3 & 24,5 & 7 \\
$\mathbf{3}$ & 5,5 & 3,4 & 14 & 3 & 35,0 & 10 \\
$\mathbf{4}$ & 6,7 & 4,2 & 16 & 3 & 45,5 & 13 \\
$\mathbf{5}$ & 8,0 & 5,0 & 18 & 3 & 56,0 & 16 \\
$\mathbf{6}$ & 8,8 & 5,5 & 20 & 3 & 66,5 & 19 \\
$\mathbf{7}$ & 9,6 & 6,0 & 22 & 3 & 77,0 & 22 \\
\hline \hline
\end{tabular}

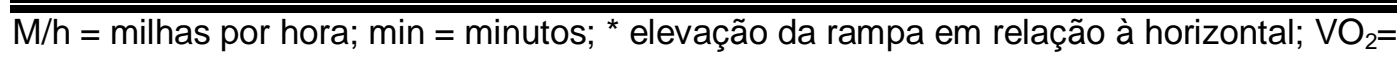
consumo de oxigênio; $\mathrm{MET}$ = consumo de oxigênio em unidades metabólicas

Foram selecionados 611 pacientes, e 18 pacientes não realizaram o TE por motivos sociais. Em 58 pacientes, o TE foi considerado inconclusivo (presença de bloqueio de ramo esquerdo, fibrilação atrial e sobrecarga ventricular esquerda) e em 163 pacientes, o exame foi considerado ineficaz, não atingido a frequência cardíaca submáxima. A frequência cardíaca submáxima foi definida com base no critério de $85 \%$ da frequência cardíaca máxima prevista para a idade. 
O cálculo da frequência cardíaca máxima utilizado foi o comumente derivado da fórmula (Karvonen et al., 1957):

\section{Frequência cardíaca máxima = 220 - idade do paciente (anos)}

Quando os pacientes agendaram o TE receberam as orientações seguintes:

Quanto ao vestuário: usar preferencialmente calção ou bermuda e calçado com solado de borracha, e o ideal é tipo tênis. No caso de mulheres, o uso do sutiã é fundamental.

Quanto às medidas higienodietéticas: permanecer sem ingerir cafeína (café, chocolate e chá) nas 24 h que antecederam o TE, abster-se de fumar 3h antes da prova, ingerir refeição leve $1 \mathrm{~h}$ a $2 \mathrm{~h}$ antes da realização do exercício. No início da manhã, realizar o desjejum habitual, exceto a ingestão de cafeína. Evitar bebidas alcoólicas 24h antes do teste.

Quanto à realização de atividade física prévia: evitar esforços não habituais ou treinamento físico no dia marcado. Além disso, é importante preservar o horário de sono na véspera do exame e não suspender o uso das medicações.

No momento antecedente à realização do TE, na fase pré-teste foram obtidos dados da ficha cadastral; peso e altura; tricotomia, caso houvesse necessidade; limpeza da pele nos locais determinados para colocação dos eletrodos, com abrasão da pele por lixas ultrafinas com movimentos leves somente em um sentido; colocação de eletrodos descartáveis e anamnese 
dirigida, além de exame cardiovascular e ausculta pulmonar. Ainda com o paciente em repouso, foi realizado um registro eletrocardiográfico basal com 15 derivações simultâneas e a aferição da pressão arterial.

Após iniciar o esforço físico foram registrados eletrocardiogramas a cada mudança de estágio e conforme a necessidade, clínica ou eletrocardiográfica, como arritmias e bloqueios, e relato de sua provável origem, complexidade, frequência e momento de aparecimento, até o final do esforço. A pressão arterial também foi aferida antes da mudança de cada estágio de Bruce, durante todo o esforço. Ao iniciar a fase de recuperação, foram registrados eletrocardiogramas e aferida a pressão arterial a cada minuto, até o sexto minuto da recuperação. Em casos de persistência das alterações tanto eletrocardiográficas quanto pressóricas até o sexto minuto da recuperação, mantinha-se os pacientes sob monitorização contínua até a normalização dessas alterações.

Os critérios de interrupção do esforço foram: critérios hemodinâmicos (pressão arterial diastólica (PAD) $\geq 120 \mathrm{mmHg}$ em normotensos, PAD $\geq 140 \mathrm{mmHg}$ em hipertensos, pressão arterial sistólica (PAS) $\geq 260 \mathrm{mmHg}$, queda da PAS $>20 \mathrm{mmHg}$ ), critérios clínicos (angina progressiva, sinais de baixo débito: ataxia, tontura, cianose, palidez e pré-síncope, dispnéia progressiva, incoordenação motora, sintomas de insuficiência vascular periférica, cansaço físico intenso ou exaustão) e critérios eletrocardiográficos (supradesnível do segmento ST em área sem onda $Q$, infradesnível do segmento $\mathrm{ST} \geq 3 \mathrm{~mm}$, arritmia ventricular complexa, taquicardia sustentada, 
bloqueio atrioventricular de segundo ou terceiro grau e alargamento do QRS de difícil distinção com taquicardia ventricular).

O desnível do segmento ST foi medido no ponto $\mathrm{Y}$ (ponto que dista 0,08s ou $80 \mathrm{~ms}$ do ponto J), e a linha de base ou de referência é representada pela união das junções $P Q$ (término do segmento PR e início do complexo QRS) de pelo menos três complexos sucessivos. A medida do desnivelamento é dada em milímetro ou em milivolt $(\mathrm{mV})$. Quando desnivelamentos do segmento ST estavam presentes desde a fase de repouso, o valor numérico foi descontado da alteração máxima obtida durante e após a fase de exercício. No caso de morfologia descendente do segmento ST, o desnivelamento foi medido a $80 \mathrm{~ms}$ do ponto $\mathrm{J}$ e, da mesma forma, as alterações máximas obtidas durante o teste, descontadas dos valores obtidos em repouso.

Os critérios de positividade foram os classicamente adotados pela Diretriz Brasileira de Ergometria (Arquivos Brasileiros de Cardiologia, 2002), infradesnível do segmento ST $\geq 1 \mathrm{~mm}$ de morfologia horizontal ou descendente ou supradesnível do segmento ST $\geq 1 \mathrm{~mm}$, durante ou após o esforço físico.

O teste positivo indica que houve alteração morfológica do segmento ST com magnitude suficiente para caracterização de isquemia miocárdica. 


\subsection{Escore clínico simplificado ou escore de Hubbard}

O escore de Hubbard (Hubbard et al., 1992) foi validado retrospectivamente em uma população consecutiva e sintomática, submetida à investigação de DAC, por meio de cintilografia de perfusão miocárdica sob estresse físico e cineangiocoronariografia em até seis meses. Foram avaliadas 16 variáveis clínicas e o eletrocardiograma de repouso a fim de desenvolver um sistema preditor acurado de coronariopatia grave em diferentes faixas etárias. Mediante análise de regressão logística, foram selecionadas cinco variáveis, que resultaram num escore simplificado de cinco pontos que fornece estimativas probabilísticas de coronariopatia grave, demonstrando que a gravidade da DAC aumenta em função da pontuação.

Tal escore considera cinco variáveis essencialmente clínicas e seu cálculo resulta da simples soma de um ponto para cada um dos parâmetros seguintes: gênero masculino, história de infarto do miocárdio e/ou ondas $Q$ no eletrocardiograma, angina pectoris típica, diabetes mellitus e ainda um ponto para cada década de vida a partir dos 40 anos, como demonstrado na Tabela 2. 
Tabela 2. Escore de Hubbard.

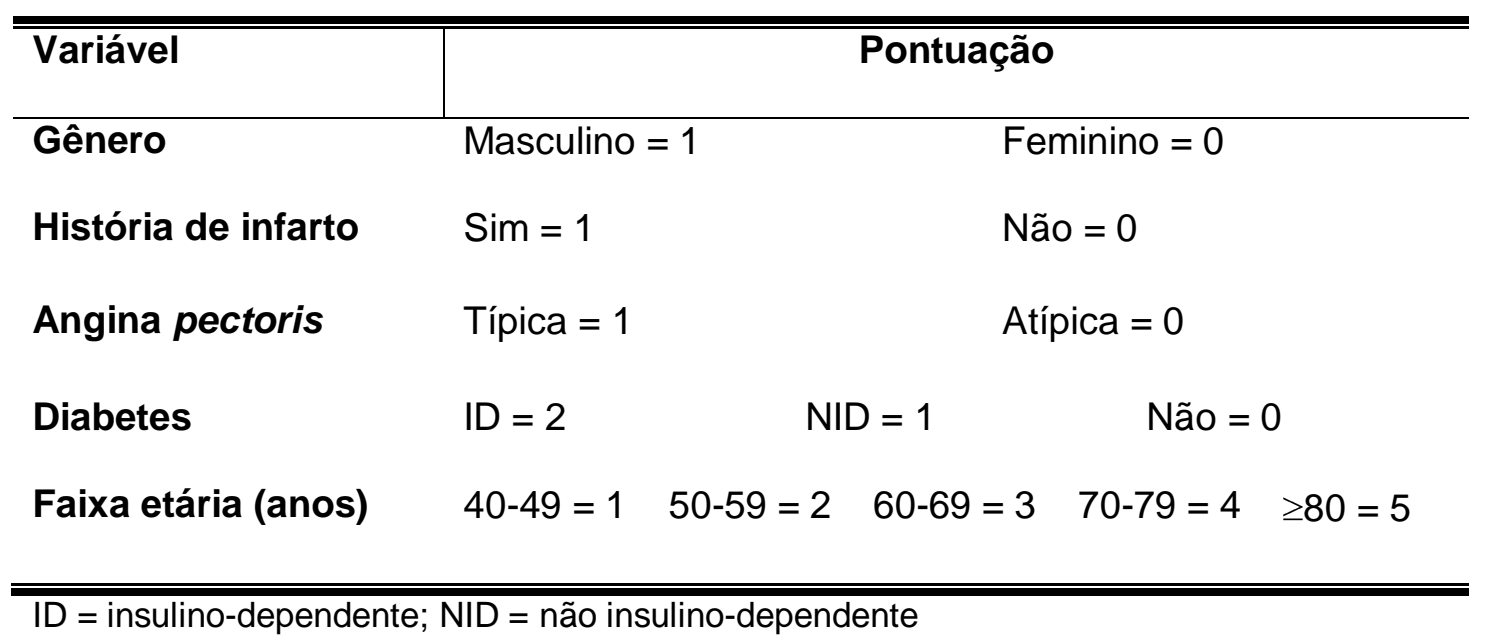

A pontuação é dada de acordo com:

1. Gênero. Quando o gênero é masculino incorpora-se um ponto ao escore, enquanto que para o gênero feminino nenhum ponto é adicionado.

2. História de infarto do miocárdio. Avaliação mediante anamnese ou confirmação do diagnóstico por presença de ondas $Q$ patológicas no eletrocardiograma de repouso.

3. Angina pectoris. Somente quando a angina é considerada típica, adicionase um ponto ao escore. A angina é definida como típica, quando há relato de dor precordial ou retroesternal em queimação ou peso, com ou sem irradiação (membro superior esquerdo, pescoço ou dorso), com duração de até $5 \mathrm{~min}$ (Wu et al., 2005), desencadeada aos esforços físicos (principalmente subir ladeira) ou por outro agente estressor. A angina é considerada atípica quando há presença de dor torácica em pontada, bem localizada, de longa duração, que piora com a palpação local ou com a inspiração profunda. 
4. Diabetes Mellitus. Adiciona-se um ponto ao escore quando há confirmação laboratorial prévia de glicemia de jejum com nível superior a $126 \mathrm{mg} / \mathrm{dL}$. O uso regular de insulina determina mais um ponto adicional. Sendo assim o diabético insulino-dependente recebe dois pontos ao escore.

5. Faixa etária. Até 39 anos não se adiciona pontos, de 40 a 49 anos somase um ponto, 50 a 59 anos, dois pontos, 60 a 69 anos, três pontos, 70 a 79 anos, quatro pontos e 80 a 89 anos, cinco pontos.

O escore varia de zero a 10 pontos, estimando a probabilidade de doença coronária em três grupos: alta ( $>5$ pontos), intermediária ( $=5$ pontos) e baixa ( $<5$ pontos).

Existem algumas limitações para a aplicação do escore de Hubbard nas situações clínicas seguintes: portador de valvopatia grave, presença de hipertrofia ventricular esquerda, nas cardiomiopatias ou no portador de incapacidade física.

\subsection{Desenvolvimento de escore novo}

O novo escore foi estruturado a partir da somatória simples das variáveis do escore de Hubbard et al. (1992), incorporando também o resultado do TE, caracterizando assim um escore pós-teste. Quando o TE resulta positivo, adiciona-se um ponto. TE negativo não determina pontuação adicional (Anexo). Assim, a pontuação total do escore novo pode 
variar de 0 a 11 pontos conforme ilustra a Tabela 3.

Tabela 3. Novo escore para estratificação de risco do paciente com DAC estável. O cálculo resulta da somatória dos pontos correspondentes às variáveis listadas.

\begin{tabular}{|c|c|}
\hline Variável & Pontuação \\
\hline \multicolumn{2}{|l|}{ Gênero } \\
\hline Feminino & 0 \\
\hline Masculino & 1 \\
\hline \multicolumn{2}{|c|}{ História de infarto do miocárdio } \\
\hline Não & 0 \\
\hline Sim & 1 \\
\hline \multicolumn{2}{|l|}{ Angina pectoris } \\
\hline Atípica & 0 \\
\hline Típica & 1 \\
\hline \multicolumn{2}{|l|}{ Diabetes mellitus } \\
\hline Ausente & 0 \\
\hline Não insulino-dependente & 1 \\
\hline Insulino-dependente & 2 \\
\hline \multicolumn{2}{|l|}{ Faixa etária (anos) } \\
\hline$<40$ & 0 \\
\hline 40 a 49 & 1 \\
\hline 50 a 59 & 2 \\
\hline 60 a 69 & 3 \\
\hline 70 a 79 & 4 \\
\hline$\geq 80$ & 5 \\
\hline \multicolumn{2}{|l|}{ Teste de esforço } \\
\hline Negativo & 0 \\
\hline Positivo & 1 \\
\hline
\end{tabular}


Para inclusão no novo escore considerou-se somente a categorização dicotômica positivo/negativo. Parâmetros clínicos e hemodinâmicos do TE não foram incorporados na análise prognóstica do escore.

Foi considerado teste positivo, a presença de depressão do segmento ST $\geq 1 \mathrm{~mm}$ de morfologia horizontal ou descendente, durante ou após o exercício, e a magnitude do desnível foi aferida a $80 \mathrm{~ms}$ do ponto $\mathrm{J}$; ou presença de elevação do segmento $S T \geq 1,0 \mathrm{~mm}$ em derivações sem ondas Q patológicas, de acordo com as recomendações das diretrizes americana e brasileira sobre TE (Arquivos Brasileiros de Cardiologia, 2002; Gibbons et al., 2002).

O resultado positivo foi considerado como a prova documental da isquemia miocárdica, adicionando um ponto no novo escore prognóstico. $\mathrm{O}$ resultado negativo foi considerado como ausência de documentação de isquemia miocárdica e sem valor prognóstico adicional no escore.

\subsection{Análise estatística}

A associação entre o escore novo e cada um dos desfechos foi analisada por regressão de Cox (1972), inclusive para identificar subgrupos de alto risco. A curva de sobrevida cardiovascular foi gerada de acordo com método de Kaplan e Meier (1958), e o teste Log-Rank aplicado para comparar essas curvas de sobrevida. Para todas as análises o valor-p para $p<0,05$ foi considerado estatisticamente significante. 
Todos os dados foram analisados de acordo com a intenção de princípio de tratamento e não o tratamento recebido. O tempo de sobrevida livre de evento foi definido como o intervalo entre a avaliação randômica e a ocorrência do desfecho primário ou o último seguimento. As variáveis contínuas foram estimadas como o valor da média, mais ou menos desvio padrão (DP) e comparadas entre os três grupos por análise de variância univariada seguida de teste de comparação múltipla. O teste do Quiquadrado e o teste exato de Fisher foram usados para comparar variáveis qualitativas entre os três grupos de tratamento. Neste caso um valor de $p=0,05$ foi considerado estatisticamente significante.

A análise estatística foi realizada com auxílio do software SAS Institute, Cary, North Carolina. 
4 RESULTADOS 


\section{RESULTADOS}

Dos 372 pacientes estudados, 156 pacientes (41,9\%) tinham história de infarto do miocárdio, $334(89,7 \%)$ apresentavam angina ao menos classe funcional II, 137 (36,8\%) eram diabéticos destes 16 (0,11\%) usuários regulares de insulina.

Durante o período total de seguimento, observou-se 29 episódios de infarto do miocárdio não-fatal, isto é, 11 no grupo ATC, seis no grupo RM e 12 no grupo TC, e essa diferença estatística entre os grupos foi considerada não significativa $(p=0,21)$.

Com relação à necessidade de RM após a randomização, observouse seis casos no grupo ATC, dois casos no grupo RM e 16 casos no grupo TC, e essa diferença entre os grupos foi considerada estatisticamente significante $(p=0,001)$.

A necessidade de ATC após a randomização foi observada em 18 casos no grupo ATC, três casos no grupo RM e em quatro casos no grupo TC, e essa diferença entre os grupos foi considerada estatisticamente significante $(p=0,001)$.

Foram observados 36 óbitos durante todo o período de seguimento, isto é, 10 no grupo ATC, 15 no grupo RM e em 11 casos no grupo TC, e essa diferença entre os grupos foi considerada estatisticamente não significante $(p=0,61)$.

O total de eventos combinados (infarto do miocárdio não-fatal, óbito e 
necessidade de re-intervenção) foi de 93, com distribuição entre os grupos seguinte: 37 no grupo ATC, 23 no grupo RM e 33 no grupo TC, com diferença estatística marginalmente significante $(p=0,058)$.

Quando foi avaliada a idade, para os diferentes grupos, não se observou diferença estatisticamente significativa $(p=0,73)$, com idade média de $59,75 \pm 9,5$ anos para o grupo ATC (127 pacientes), 59,97 $\pm 8,4$ anos para o grupo RM (130 pacientes) e 59,08 $\pm 9,3$ anos para o grupo TC (115 pacientes).

Com relação ao gênero, um escore inferior a seis pontos foi observado em 97 homens e em 59 mulheres. Escore igual ou superior a seis pontos foi observado em 169 homens e em 47 mulheres.

Do total de pacientes analisados, 247 (66,4\%) apresentaram escore de Hubbard $\geq 5$ pontos e $216(58 \%) \geq 6$ pontos, como mostram as Tabelas 4 e 5 . O valor de corte $\geq 5$ ou $\geq 6$ pontos permitiu identificar indivíduos com maior risco de óbito, com $p=0,015$ e $p=0,012$, respectivamente.

Ao comparar os dois escores, observou-se que 31 pacientes foram classificados com alto risco pelo escore de Hubbard, mas considerados com baixo risco pelo escore novo. Nenhum indivíduo de baixo risco pelo escore de Hubbard foi classificado como de alto risco no escore novo. A diferença da classificação de risco entre os escores foi considerada estatisticamente significante $(p=0,001)$, como mostra a Tabela 5 . 
Tabela 4. Distribuição de pacientes dos diferentes grupos de tratamento conforme pontuação dos escores de Hubbard e do novo escore.

\begin{tabular}{c|ccc|c}
\hline \hline \multirow{2}{*}{} & \multicolumn{4}{|c}{ Quantidade de pacientes } \\
\cline { 2 - 5 } & \multicolumn{2}{|c}{ Escore de Hubbard } & \multicolumn{2}{c}{ Novo escore } \\
\cline { 2 - 5 } ATC & $<$ pontos & $\geq$ 5 pontos & $<$ pontos & $\geq 6$ pontos \\
RM & 45 & 82 & 53 & 74 \\
TC & 39 & 91 & 50 & 80 \\
& 41 & 74 & 53 & 62 \\
& & $\mathrm{p}=0,015$ & & $\mathrm{p}=0,012$ \\
\hline \hline
\end{tabular}

ATC = Angioplastia transluminal coronária; RM = Revascularização miocárdica; TC = Tratamento clínico; $p=$ valor- $p$

Tabela 5. Comparação entre os escores. Distribuição dos pacientes conforme pontuação nos dois escores.

\begin{tabular}{l|cc}
\hline \hline Novo Escore & \multicolumn{2}{|c}{$\begin{array}{c}\text { Escore de Hubbard } \\
\text { (quantidade de pacientes) }\end{array}$} \\
\hline Pontuação & $<5$ pontos & $\geq 5$ pontos \\
$<6$ pontos & 125 & 31 \\
$\geq 6$ pontos & 0 & 216 \\
TOTAL & 125 & 247 \\
\hline \hline
\end{tabular}

A necessidade de RM após a randomização foi observada em oito pacientes com escore $<6$ pontos e em 16 pacientes com escore $\geq 6$ pontos $(p=0,37)$. 
A necessidade de ATC após a randomização foi observada em 12 pacientes com escore $<6$ pontos e em 13 pacientes com escore $\geq 6$ pontos ( $p$ $=0,52)$.

A incidência de óbito após a randomização foi observada em 10 pacientes com escore $<6$ pontos e em 26 pacientes com escore $\geq 6$ pontos ( $p$ $=0,07)$.

A incidência de eventos combinados após a randomização foi observada em 34 pacientes com escore $<6$ pontos e em 59 pacientes com escore $>6$ pontos $(p=0,22)$.

De acordo com a análise da curva de sobrevida observou-se que não houve diferença estatisticamente significante na incidência de eventos combinados para os pacientes com escore de Hubbard $<5$ ou $\geq 5$ pontos $(p=0,062)$, conforme ilustra a Figura 2. 


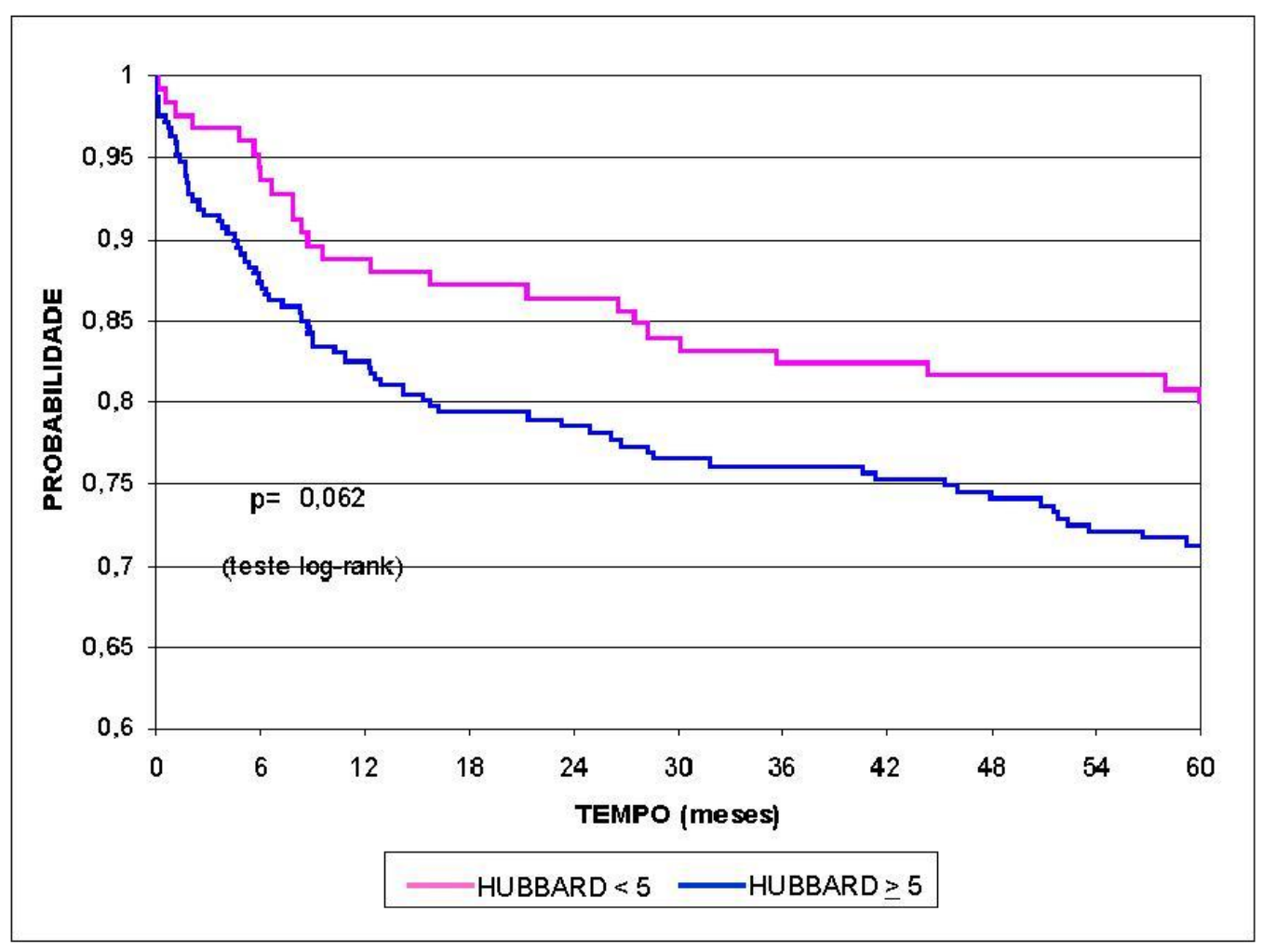

Figura 2. Comparação da taxa de eventos combinados entre os pacientes com escore de Hubbard $<5$ ou $\geq 5$ pontos.

Ao avaliar a incidência de eventos combinados para o novo escore, observou-se diferença estatisticamente significante $(p=0,02)$ entre os pacientes com escore $<6$ e $\geq 6$ pontos, conforme ilustram as respectivas curvas comparativas de sobrevida na Figura 3. 


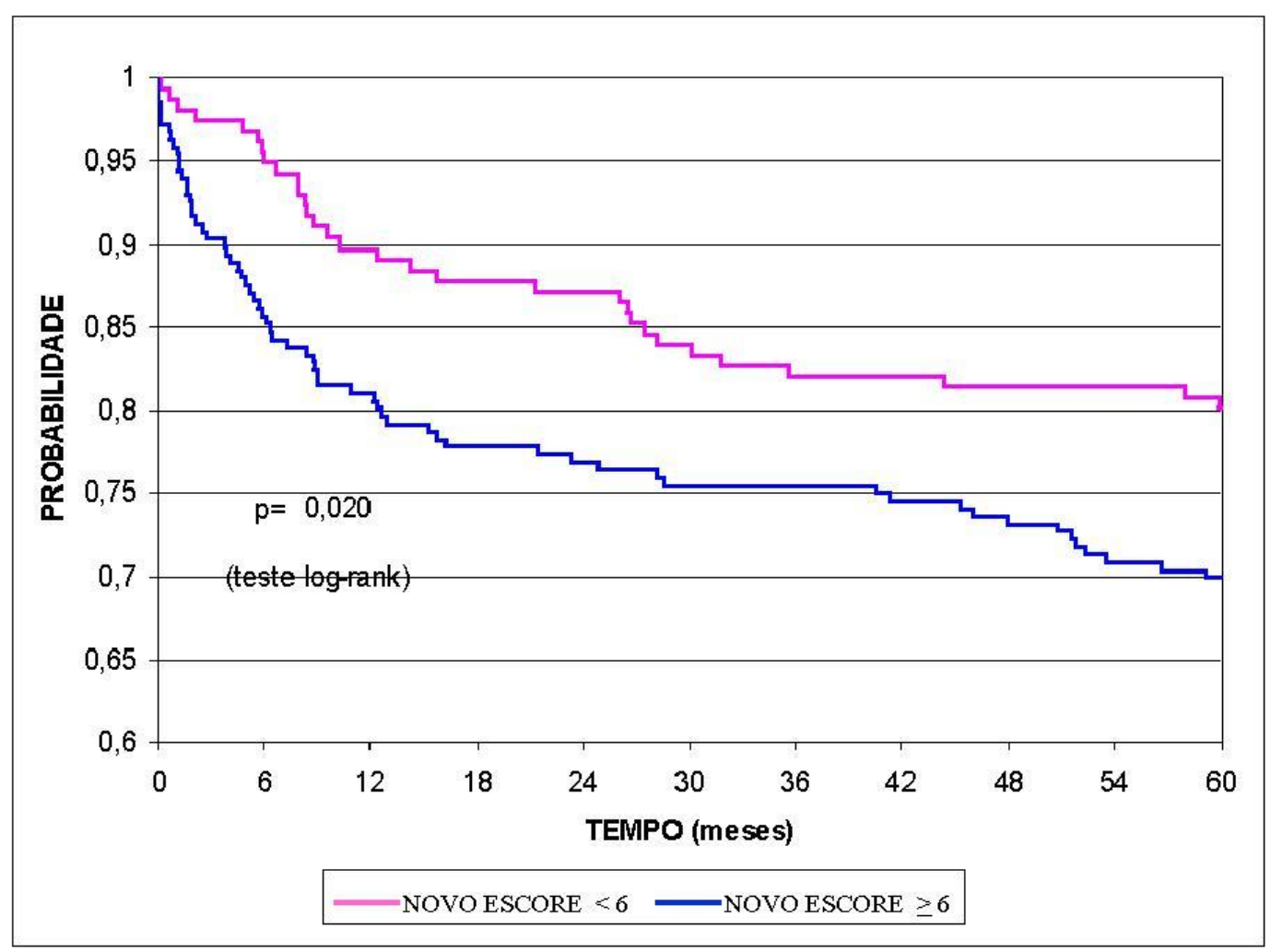

Figura 3. Comparação da taxa de eventos combinados entre os pacientes com o novo escore $<6$ ou $\geq 6$ pontos.

A incidência de óbito cardiovascular foi maior nos pacientes com escore $\geq 5$ pontos de acordo com o escore de Hubbard, com diferença estatisticamente significante $(p=0,015)$, como mostra a Figura 4. 


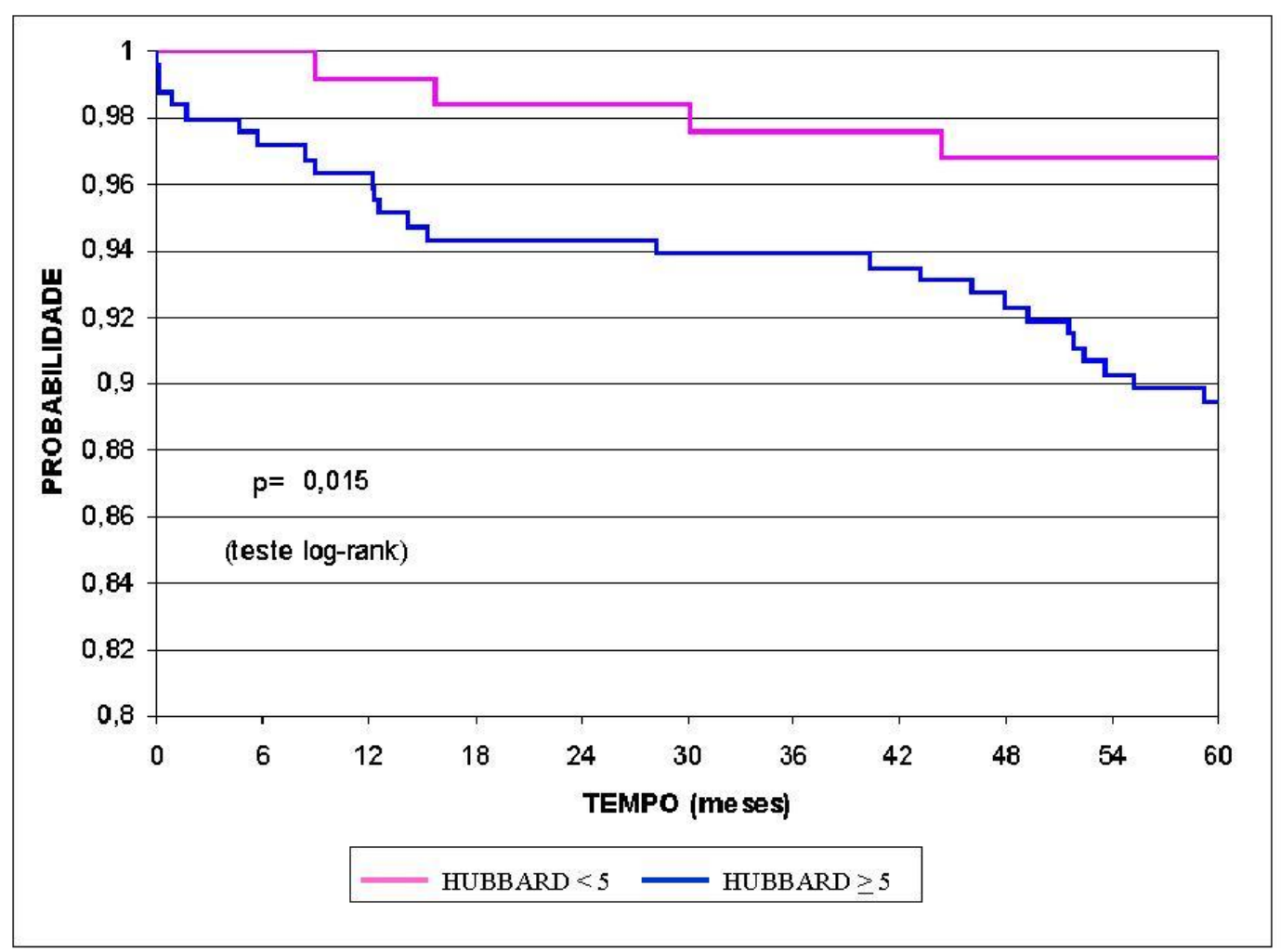

Figura 4. Comparação entre a taxa de óbito cardiovascular para os pacientes que apresentaram escore de Hubbard com $<5$ pontos e $\geq 5$ pontos.

A diferença na incidência de óbito foi mais significante entre os pacientes com escore $<6$ e $\geq 6$ pontos, com $p=0,004$, como ilustra a Figura 5 . 


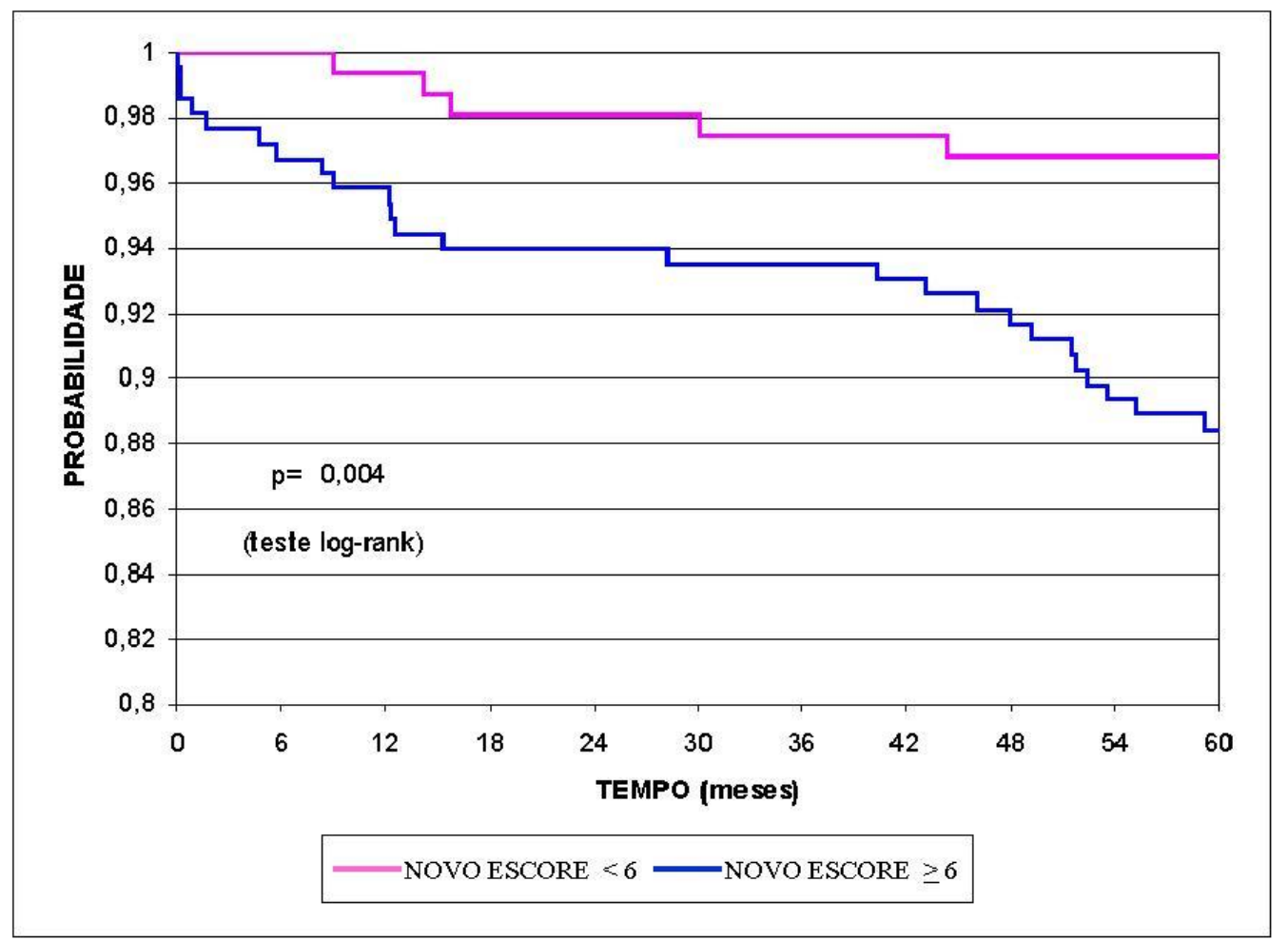

Figura 5. Comparação entre a taxa de óbito cardiovascular para pacientes com escore novo de $<6$ pontos $e \geq 6$ pontos.

Em relação ao desfecho primário, a análise da curva de sobrevida não demonstrou diferença entre os três grupos de tratamento, como ilustra a Figura 6. 


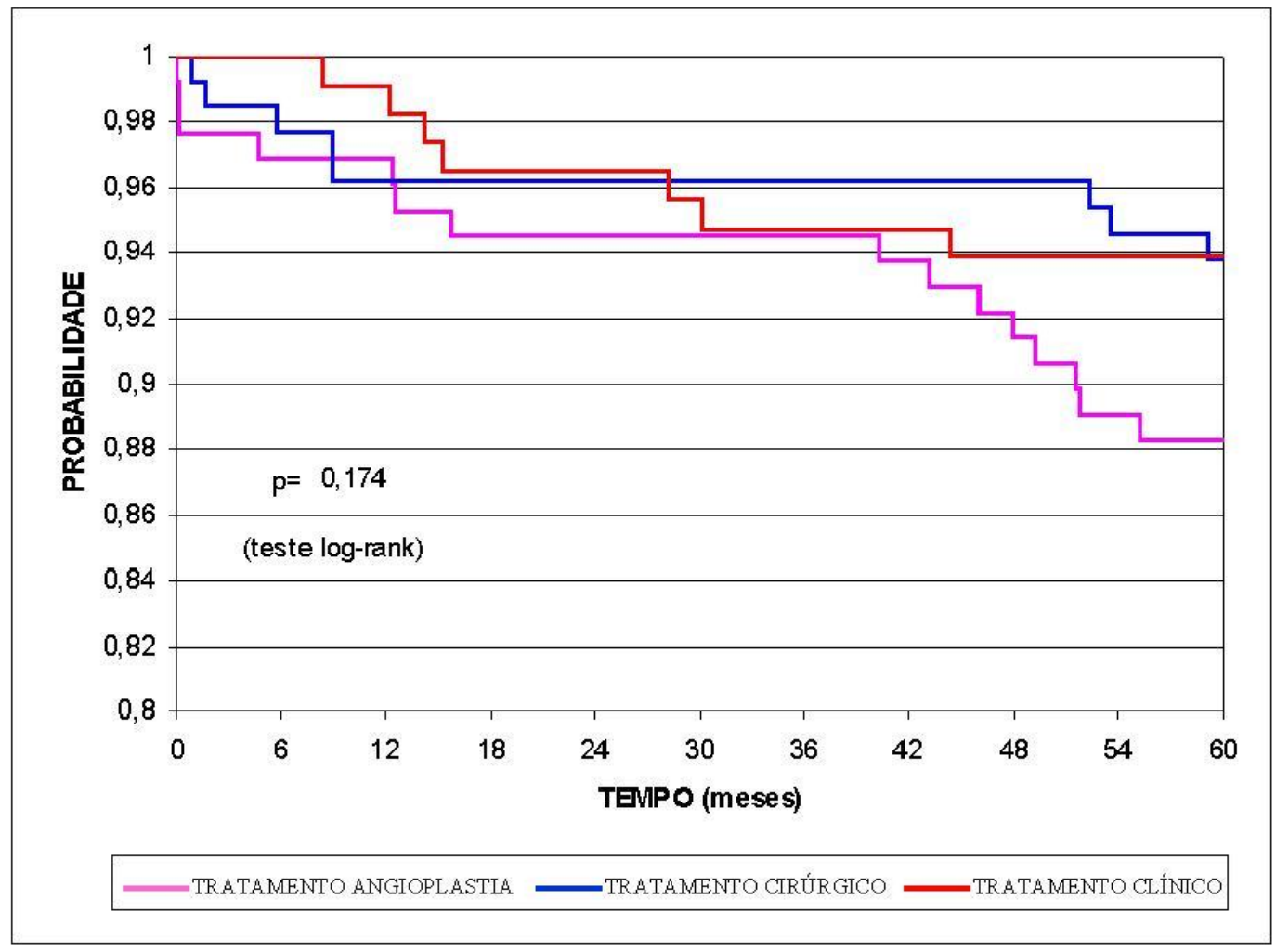

Figura 6. Análise da curva de sobrevida em relação ao desfecho primário ao comparar os três grupos de tratamento.

Em relação à incidência de óbito e escore de Hubbard $\geq 5$, observaram-se 15 óbitos no grupo ATC, 12 no grupo RM e 10 no grupo TC, $(p=0,59)$, enquanto com escore $<5$ pontos, foi observado um óbito no grupo ATC, cinco óbitos no grupo RM e três no grupo TC $(p=0,176)$.

Com relação à incidência de óbitos e a pontuação do novo escore $\geq 6$, ocorreram 11 óbitos no grupo ATC, sete no grupo RM e seis no grupo TC, $(p=0,4)$. Quando a pontuação do novo escore foi inferior a seis pontos evidenciaram-se um óbito no grupo ATC, 6 no grupo RM e 3 no grupo TC $(P=0,163)$, como mostra a Tabela 6. 
Tabela 6. Quantidade de óbitos ao comparar o novo escore e o escore de Hubbard para os três grupos de tratamento, durante os cinco anos de seguimento.

\begin{tabular}{|c|c|c|c|c|}
\hline \multirow{3}{*}{ Variável } & \multicolumn{4}{|c|}{ Quantidade de óbitos } \\
\hline & \multicolumn{2}{|c|}{ Novo escore } & \multicolumn{2}{|c|}{ Escore de Hubbard } \\
\hline & $\geq 6$ pontos & $<6$ pontos & $\geq 5$ pontos & $<5$ pontos \\
\hline ATC & 11 & 1 & 15 & 1 \\
\hline $\mathbf{R M}$ & 7 & 6 & 12 & 5 \\
\hline $\mathrm{TC}$ & 6 & 3 & 10 & 3 \\
\hline $\mathbf{p}$ & $\mathrm{p}=0,4$ & $p=0,163$ & $\mathrm{p}=0,59$ & $p=0,176$ \\
\hline
\end{tabular}

A análise da incidência de eventos combinados para os diferentes grupos de tratamento mostrou que o grupo RM apresentou a menor taxa de eventos $(p<0,001)$.

Quanto à ocorrência de eventos combinados, para os pacientes aos quais se atribuiu o escore de Hubbard $\geq 5$ pontos, se observou 33 eventos no grupo ATC, 13 no grupo RM e 23 no grupo TC, com uma incidência de eventos com significância reduzida no grupo $R M(p<0,001)$. A análise da incidência de eventos combinados para os pacientes com escore de Hubbard inferior a cinco pontos, mostrou a ocorrência de um evento no grupo ATC, cinco eventos no grupo RM e três no grupo TC ( $P=0,24)$. Esses dados são mostrados na Tabela 7.

Ao analisar a incidência de eventos combinados nos pacientes com pontuação igual ou superior a 6 pontos pelo novo escore, observaram-se 24 eventos no grupo ATC, 8 no grupo RM e 12 no grupo TC $(p=0,001)$. Nos 
pacientes com escore inferior a 6 pontos observamos 9 eventos no grupo ATC, 5 no grupo RM e 9 no grupo TC $(P=0,334)$. Esses dados também estão demonstrados na Tabela 7.

Tabela 7. Quantidade de eventos combinados ao comparar o escore novo e o escore de Hubbard, para os diferentes grupos de tratamento durante cinco anos de seguimento.

\begin{tabular}{l|c|c|c|c}
\hline \hline \multirow{2}{*}{ Variável } & \multicolumn{4}{|c}{ Quantidade de eventos } \\
\cline { 2 - 5 } & \multicolumn{2}{|c}{ Escore novo } & \multicolumn{2}{c}{ Escore de Hubbard } \\
\cline { 2 - 5 } & $\geq \mathbf{6}$ pontos & $<$ 6 pontos & $\geq$ 5 pontos & $<5$ pontos \\
\hline ATC & 24 & 9 & 33 & 1 \\
RM & 8 & 5 & 13 & 5 \\
TC & 12 & 9 & 23 & 3 \\
$\mathbf{p}$ & 0,001 & 0,334 & $<0,001$ & 0,24 \\
\hline \hline
\end{tabular}

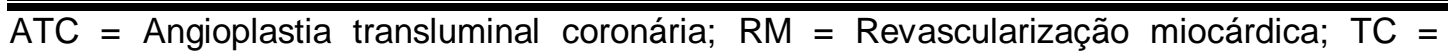
Tratamento clínico; $p=$ valor $p$. 


\section{DISCUSSÃO}




\section{DISCUSSÃO}

A avaliação prognóstica é um componente crucial da avaliação clínica em todos os níveis de assistência da DAC. Embora os pacientes com angina estável apresentem mortalidade baixa (Fox, 2003; Yusuf et al., 2000; Kaplan e Meyer, 1958), o risco de infarto do miocárdio, a necessidade de intervenções e os sintomas impactam sobre a evolução clínica de maneira representativa. Como o benefício absoluto de qualquer tratamento, para melhorar o prognóstico, depende do risco de eventos. Estes são especialmente considerados se 0 tratamento apresenta complicações potencialmente graves.

Escores prognósticos para o portador de angina estável são poucos, embora vários tenham sido desenvolvidos para estratificação de DAC com aplicação de parâmetros clínicos e do TE, ou combinados (Yamada et al., 1997; Pryor et al., 1991), com o agravante de que ainda existe uma porcentagem de indivíduos que é incapaz de se exercitar de modo adequado (Prakash et al., 2001; Mark et al., 1987).

A proposta do presente estudo foi desenvolver um índice para estratificação de risco do coronariopata estável multiarterial, por meio de um método simples e acessível, contrastando com a ampla gama de procedimentos de custo alto e complexidade disponíveis na prática clínica.

Na casuística presente, a idade média de 59,5 anos, determinou um valor inicial maior do escore. Assim, a amostra representou uma faixa etária 
mais alta, portanto, com um perfil de risco maior. O predomínio do gênero masculino na amostra estudada não teve impacto sobre a interpretação dos resultados por causa da presença documentada de DAC multiarterial em ambos os gêneros.

A maioria dos homens $(63,29 \%)$ apresentou escore $\geq 6$ pontos, enquanto para a grande parte das mulheres foi observado um escore $<6$ pontos. A pontuação maior para os homens pode estar relacionada ao fato de que o gênero masculino está associado a uma pontuação adicional. Além disso, infarto do miocárdio é mais comum em homens, porém as mulheres apresentam um prognóstico pior, por causa da maior incidência de óbito e re-infarto, conforme demonstrado no estudo de Framingham (Yamada et al., 1997). Com relação à dor precordial, embora ela seja mais frequente em mulheres, a prevalência de DAC angiográfica significante é menor, determinando um valor preditivo menor para os testes não-invasivos (Arquivos Brasileiros de Cardiologia, 2004; Gibbons, 1993).

De forma geral, a prevalência de doença coronária é menor em mulheres, entretanto, aos 65 anos as mulheres apresentam o risco de infarto do miocárdio semelhante ao homem, com taxa de mortalidade $11 \%$ maior, com mais complicações e maior taxa de mortalidade precoce nos procedimentos de revascularização (Kannel et al., 1979). Quando a doença coronária se manifesta nas mulheres, elas estão mais idosas, conseqüentemente com sintomas mais instáveis e com maior número de comorbidades, que além de complicar a evolução natural da doença, 
contribuem para um maior número de eventos adversos (Kannel et al., 1979).

$\mathrm{Na}$ análise prognóstica não foi considerada a diferença entre os padrões angiográficos bi ou triarterial em virtude de uma quantidade baixa de desfechos no período de seguimento.

A taxa de óbitos (10,33\%) observada na casuística presente, durante os anos de seguimento, foi superior à mortalidade geral de pacientes com angina estável, que está ao redor de 1\% ao ano, segundo dados da diretriz sobre angina estável (Arquivos Brasileiros de Cardiologia, 2004). Isto pode ser explicado por causa da quantidade maior de pacientes de alto risco no presente estudo, com maior prevalência de portadores de obstruções coronárias múltiplas e de diabéticos, apesar de apresentar a função ventricular esquerda preservada.

A incidência de eventos combinados e a necessidade de reintervenção com angioplastia após a randomização foi maior no próprio grupo ATC. Provavelmente, isto está relacionado a uma taxa de reestenose maior, pois uma parte representativa da amostra era de diabéticos nos quais taxas maiores de reestenose são comumente encontradas (Singh et al., 2004; Kastrati et al., 1987).

A quantidade elevada de diabéticos (36,8\%) determinou também uma pontuação inicial maior no escore, compatível com o fato de que os portadores de diabetes possuem maior incidência de coronariopatia grave. A prevalência de DAC em diabéticos é estimada em $55 \%$, comparada com $2 \%$ a 4\% na população em geral. Está bem definido que o diabetes é um fator 
de risco maior para eventos coronários (Wilson et al., 1998) tanto o tipo 1 (Lloyd et al., 1996) quanto o tipo 2 (Wilson, 1998). O diabetes tipo 2 é de particular importância, pois, é mais comum e ocorre com frequência em pessoas idosas, quando múltiplos fatores de risco coexistem. Há uma aceitação crescente que a maioria dos diabéticos, principalmente os do tipo 2, sejam classificados como de alto risco em curto prazo. Outra razão para elevar o diabético para uma categoria de maior risco é o seu pior prognóstico, uma vez que este tipo de doente desenvolve coronariopatia (Stone et al., 1989).

Em relação ao TE, os pacientes diabéticos representam um grupo particularizado, isto é, apresentam uma incidência maior de hipertensão arterial, vasculopatia periférica, neuropatia periférica, grande parte é obesa e apresenta capacidade funcional reduzida. Além disso, com maior frequência estão expostos ao uso de medicamentos que limitam a frequência cardíaca (beta-bloqueadores e bloqueadores de canais de cálcio). Dessa forma, quando múltiplos fatores de risco coexistem, existe limitação para que se atinja um risco baixo no escore de Duke. Além disso, o nível de esforço físico pode não ser suficiente para a documentação de isquemia miocárdica, mesmo com eventual DAC significante, cuja prevalência é maior nesses pacientes.

O escore de Duke foi desenvolvido por Mark et al. (1987), ao utilizar dados coletados de prontuários de pacientes hospitalizados com diagnóstico presuntivo ou definido de coronariopatia, todos submetidos a cateterismo cardíaco. Inicialmente, foi considerado o caráter prognóstico (Mark et al., 
1991), no qual o desfecho considerado foi a sobrevida livre de infarto, excluindo aqueles submetidos a intervenções. O modelo de risco de Cox foi aplicado para determinar quais variáveis do TE foram associadas de forma independente e significante. Assim, o escore de Duke foi composto por três variáveis e seus coeficientes são:

1) magnitude do desnível do segmento ST;

2) capacidade funcional;

3) angina intra-esforço.

A fórmula para o cálculo do escore de Duke é dada por:

\section{Escore de Duke $=$ tempo de exercício $(\mathrm{min})-[5 \mathrm{x}$ desnível ST(mm) -4 x índice de angina]}

O tempo de exercício é medido em minutos do protocolo de Bruce (em outros protocolos é necessário fazer a equivalência em MET ao protocolo de Bruce), o desnível ST em milímetros e os índices de angina podem ser: 0 para ausência de angina, 1 ponto para angina intra-esforço e 2 pontos para angina limitante.

Interpretação. A pontuação final varia de $\geq(+15)$ (pacientes que completaram o $5^{0}$ estágio na ausência de angina) a $\leq(-25)$ pontos (esforço interrompido por angina com $\leq 3$ min e com desnível ST de $4 \mathrm{~mm}$ ), e permite classificar os indivíduos em três grupos de risco.

Atualmente o índice prognóstico mais amplamente utilizado na 
literatura, apresenta as limitações seguintes:

1. Quanto à sua indicação. A aplicação do escore de Duke é limitada no caso de assintomáticos, pós-infarto do miocárdio (recente), após revascularização miocárdica (recente), valvopatias, na dor torácica aguda e nos pacientes com análise eletrocardiográfica prejudicada para definição de isquemia miocárdica, tais como: uso de digitálicos, presença de sobrecarga ventricular esquerda, bloqueio de ramo esquerdo e pré-excitação ventricular. Em idosos, com idade superior a 75 anos, o valor prognóstico também é limitado, pois grande parte apresenta capacidade funcional reduzida que pode ser decorrente de falta de capacidade funcional, fraqueza muscular, problemas ortopédicos, neurológicos ou doença vascular periférica, além da maior incidência e severidade de DAC (Kwok et al., 2002). Muitos pacientes não são capazes de exercitar-se o suficiente para alcançar o escore de Duke que equivale a risco baixo (5min no protocolo de Bruce). Além disso, a carga de trabalho realizada pode ser inadequada para induzir isquemia; assim, o desnível do segmento ST ou a angina podem não se manifestar, mesmo estando presente uma coronariopatia grave. Isso determina uma maior taxa de idosos subestimados na classificação de grupos de risco. Além disso, o estudo que validou o escore de Duke, avaliou uma população com idade média de 49 anos, e somente uma pequena quantidade de idosos foi incluída (Mark et al., 1987). 
2. Quanto à fórmula e interpretação do escore. A análise do escore de Duke envolve cálculos complexos. O mesmo peso é conferido aos diversos tipos morfológicos das alterações do segmento ST. O infradesnível é considerado de forma semelhante ao supradesnível. O momento das alterações eletrocardiográficas não é considerado. Não se pondera as alterações hemodinâmicas nem são incorporadas as variáveis clínicas. O valor numérico dos resultados do escore não é expresso de forma clara ou direta. Os níveis de risco não apresentam correlação linear com escalas de probabilidade de doença e problemas ósteo-musculares que determinam baixo trabalho, automaticamente elevam o nível de risco.

O escore de Hubbard foi selecionado inicialmente para compor o escore novo, pois, contém variáveis clínicas de fácil avaliação, e estão presentes na anamnese rotineira. O número de variáveis é pequeno, a somatória dos pontos não implica em cálculos complexos e a interpretação é fácil, e possui correlação linear entre o resultado e o prognóstico. Além disso, Poornima et al. (2004) mostraram que tal escore pode identificar indivíduos de alto risco, mesmo quando classificados em baixo risco pelo escore de Duke. Contudo, possui limitações, como a análise exclusiva de variáveis clínicas, não considerando uma prova documental de isquemia miocárdica que comprovadamente fornece informação prognóstica adicional (Samia et al., 2005). 
Ao acrescentar a variável prova documental de isquemia miocárdica na análise, 31 pacientes foram classificados como baixo risco pelo novo escore, pois apresentavam TE negativo. Assim, o escore de Hubbard superestimou o grupo de maior risco na população estudada.

No TE, embora outras variáveis como capacidade funcional, arritmias, respostas cronotrópica e inotrópica, sejam consideradas de maior valor preditivo do que a depressão do segmento ST, existe um vício de interpretação dos resultados dos estudos. Não se considerou que na prática clínica um TE que resulta positivo acaba implicando na indicação de estudo cineangiocoronariográfico e, como consequência, de tratamento farmacológico ou procedimentos de revascularização miocárdica (cirúrgica ou percutânea). Tais intervenções terapêuticas determinam uma alteração na evolução natural da doença coronária que impacta no valor prognóstico do marcador eletrocardiográfico de isquemia miocárdica.

A análise prognóstica do escore novo não incorporou essas inúmeras variáveis específicas do TE. Adotou-se somente a documentação eletrocardiográfica de isquemia miocárdica, pois o objetivo foi aplicar um sistema prático, de fácil memorização e interpretação, para que ele seja mais amplamente aceito tanto pelo clínico quanto pelo especialista (Storti et al., 2011).

Com o uso de escores prognósticos simplificados aplicados em associação ao TE pode-se estratificar, de forma mais acurada, o coronariopata estável, e reduzir a taxa de solicitação de procedimentos de complexidade alta e otimizar a relação custo-efetividade, um aspecto 
particularmente importante na atualidade.

Os escores permitem melhorar a acurácia prognóstica do TE, diminuem vícios de interpretação e pode-se organizar as diversas informações clínicas contextuais, determinando uma redução na subjetividade e na variabilidade da estratificação de risco. Particularmente, o escore proposto no presente estudo demonstrou seu valor prognóstico de forma abrangente, por meio de uma sistemática simples e organizada. 
6 CONCLUSÕES 


\section{CONCLUSÕES}

Este novo escore é um método consistente de estratificação de risco do coronariopata estável multiarterial e acrescenta dados relevantes ao clássico escore de Hubbard. 
ANEXO 


\title{
Avaliação Prognóstica da Doença Coronariana Estável através de um Novo Escore
}

\author{
New Prognostic Score for Stable Coronary Disease Evaluation
}

Fernanda Coutinho Storti, Paulo Jorge Moffa, Augusto H. Uchida, Whady Armindo Hueb, Luiz Antônio Machado César, Beatriz Moreira Ayub Ferreira, Paulo Augusto de Camargo Jr, William Azem Chalela

Instituto do Coração - HCFMUSP - São Paulo, SP - Brasil

Resumo

Fundamento: A necessidade de melhorar a acurácia do teste de esforço, determinou o desenvolvimento de escores, cuja aplicabilidade já foi amplamente reconhecida.

Objetivo: Avaliação prognóstica do coronariopata estável através de um novo escore simplificado.

Métodos: Um novo escore foi aplicado em 372 coronariopatas multiarteriais e função ventricular preservada, $71,8 \%$ homens, idade média 59,5 $( \pm 9,07)$ anos, randomizados para angioplastia, revascularização cirúrgica e tratamento clínico, acompanhados por 5 anos. Óbito cardiovascular foi o desfecho primário. Infarto do miocárdio não-fatal, óbito e re-intervenção formaram o desfecho combinado secundário. O escore baseou-se numa equação previamente validada resultante da soma de 1 ponto para: sexo masculino, história de infarto, angina, diabete, uso de insulina e ainda 1 ponto para cada década de vida a partir dos 40 anos. Teste positivo adicionou 1 ponto.

Resultados: Ocorreram 36 óbitos (10 no grupo angioplastia, 15 no grupo revascularização e 11 no grupo clínico), p $=0,61$. Observou-se 93 eventos combinados: 37 no grupo angioplastia, 23 no grupo revascularização e 33 no grupo clínico $(p=0,058) .247$ pacientes apresentaram escore clínico $>5$ pontos e $216>6$ pontos. O valor de corte $>5$ ou $>6$ pontos identificou maior risco, com $p=0,015$ e $p=0,012$, respectivamente. A curva de sobrevida mostrou uma incidência de óbito após a randomização diferente naqueles com escore $>6$ pontos $(p=0,07)$, e uma incidência de eventos combinados diferente entre pacientes com escore $<6 \mathrm{e}>6$ pontos $(\mathrm{p}=0,02)$.

Conclusão: O novo escore demonstrou consistência na avaliação prognóstica do coronariopata estável multiarterial. (Arq Bras Cardiol 2011;96(5):411-419)

Palavras-chave: Teste de esforço, doença das coronárias, angina pectoris, prognóstico.

\section{Abstract}

Background: The need to improve the exercise testing accuracy, pushed the development of scores, whose applicability was already broadly recognized.

Objective: Prognostic evaluation of stable coronary disease through a new simplified score.

Methods: A new score was applied in 372 multivessel coronary patients with preserved ventricular function, $71.8 \%$ male, age: 59.5 ( \pm 9.07) years old, randomized to medical treatment, surgery (CABC) or angioplasty (PTCA), with 5 years of follow-up. Cardiovascular death was considered the primary endpoint. Non-fatal myocardial infarction, death and re-intervention were considered for a combined secondary endpoint. The score was based on an equation previously validated, resulting from a sum of one point for: male gender, infarction history, angina, diabetes, insulin use and one point for each decade of life after 40 years old. Positive exercise testing summed one additional point.

Results: Thirty six deaths was observed (10 in group PTCA, 15 in CABC and 11 in the clinical group), $p=0.61$. We observed 93 combined events: 37 in PTCA group, 23 in CABC and 33 in the clinical group $(p=0.058)$. 247 patients presented clinical score $\geq 5$ points and $216 \geq 6$ points. The cutoff point $\geq 5$ or $\geq 6$ points identified higher risk, $p=0.015$ and $p=0.012$, respectively. The survival curve showed a different death incidence after the randomization when score reached 06 points or more $(p=0.07)$, and a distinct incidence of combined events between the patients with score $<6$ and $\geq 6$ points $(p=0.02)$.

Conclusion: The new score was consistent for multiarterial stable coronary disease risk stratification. (Arq Bras Cardiol 2011;96(5):411-419)

Keywords: Exercise test; coronary disease; angina pectoris; prognosis. 
Storti e cols.

\section{Artigo Original}

\section{Introdução}

Mesmo com os avanços da medicina, o teste de esforço (TE) com seu baixo custo, segurança e fácil aplicabilidade é recomendado pela diretriz americana ${ }^{1}$ como o primeiro procedimento a ser realizado em pacientes com doença arterial coronariana (DAC). Assim, a maximização das informações obtidas no TE é de primordial importância e a necessidade de melhorar sua acurácia, determinou o desenvolvimento de escores, amplamente reconhecidos pela literatura científica ${ }^{2-9}$

Para uma abordagem mais didática da DAC, tais escores foram classificados em: pré-teste, pós-teste, simplificados, multivariados, diagnósticos ou prognósticos. Num escore préteste, apenas variáveis clínicas são analisadas, ao incorporar parâmetros do TE define-se um escore pós-teste ${ }^{6}$.

Dentre os escores pré-teste temos: Diamond-Forrester ${ }^{2}$, Morise e Jalisi ${ }^{3}$, Froelicher e cols. ${ }^{4}$ e Hubbard e cols. ${ }^{10}$, entre outros. Essa análise probabilística preliminar é recomendada pela diretriz americana ${ }^{1}$ sobre TE.

Entre os principais escores pós-teste temos: Mark e cols. ${ }^{7}$, Raxwal e cols. ${ }^{8}$, Morrow e cols. ${ }^{11}$, Froelicher e cols. ${ }^{4}$, Morise cols. ${ }^{3}$, Do e cols. ${ }^{9}$, Morise e cols. ${ }^{6}$, Detrano e cols. ${ }^{12}$, Lu e cols. ${ }^{13}$ Villella e cols. (GISSI 2$)^{14}$, Koide e cols. ${ }^{15}$, Hollenberg e cols. ${ }^{16}$.

Escores baseados em equações multivariadas possuem fórmulas complexas, das quais derivam escores simplificados cujos cálculos envolvem a simples somatória de pontos.

Escores diagnósticos visam a estimativa de probabilidade de DAC, podendo ter caráter prognóstico quando realizam a estimativa de doença grave (padrão triarterial ou lesão de tronco de coronária esquerda). Escores prognósticos são idealizados para avaliação de risco, principalmente, de óbito cardiovascular ou infarto não-fatal.

O escore prognóstico mais utilizado é o de Mark e cols. (Duke) $)^{17}$, e embora seja amplamente validado, não classifica adequadamente assintomáticos, idosos, pacientes no pósrevascularização do miocárdio (recente) e no pós-infarto do miocárdio recente. Além disso, ele é composto exclusivamente por dados do TE, seus resultados e sua classificação em categorias de risco são complexos e de difícil memorização.

Um escore clínico simplificado foi idealizado por Hubbard e cols. ${ }^{10}$ com intuito diagnóstico, sendo posteriormente validado $^{18}$ para análise prognóstica de DAC. Contudo, ta escore não inclui uma prova documental de isquemia em sua composição, dado que impacta no prognóstico do portador de coronariopatia.

Visando propiciar uma orientação mais completa e objetiva à estratificação de risco do coronariopata estável, propomos um novo escore pós-teste, que inclui o resultado do TE com os parâmetros do escore de Hubbard e cols. ${ }^{10}$.

\section{Métodos}

O estudo baseou-se numa análise retrospectiva de dados coletados prospectivamente do estudo (MASS-II) Hueb e cols. ${ }^{19}$, com 05 anos de seguimento. MASS refere-se a sigla de Medicine, Angioplasty or Surgery Study, cujo objetivo era avaliar, randomicamente, o tratamento de portadores de coronariopatia estável multiarterial e função ventricular preservada. O modelo do estudo, critérios de seleção e procedimentos de randomização foram previamente publicados ${ }^{20}$. O estudo foi aprovado pelo comitê científico e de ética e todos assinaram um consentimento livre e esclarecido. Todos os TE foram realizados em esteira rolante Fukuda Denshi STAR ML- 8000, com 15 derivações simultâneas e protocolo de Bruce ${ }^{21}$.

Inicialmente, foram selecionados 611 pacientes, sendo que 18 pacientes não realizaram o TE por motivos sociais, 58 tiveram o TE considerado como inconclusivo (presença de bloqueio de ramo esquerdo, fibrilação atrial e sobrecarga ventricular esquerda) e em 163 pacientes, o exame foi considerado ineficaz, por não atingir a frequência cardíaca submáxima.

Assim, a amostra final deste estudo incluiu 372 pacientes, todos com confirmação cinecoronariográfica de doença bi ou triarterial e função ventricular esquerda preservada, sendo 267 homens (71,8\%), com idade média de 59,5 ( \pm 9,07) anos, distribuídos em três grupos: angioplastia transluminal coronariana (ATC) $34,4 \%$, cirurgia de revascularização miocárdica (RM) 34,9\% e tratamento clínico (TC) 30,6\%.

O delineamento do estudo permitiu aos pacientes uma translocação entre os diversos grupos de tratamento, baseados na ocorrência de sintomas, em qualquer época do estudo. Não houve distinção nos tipos de medicamentos entre os três grupos.

Os critérios de inclusão foram:

1. Angina estável.

2. Fração de ejeção do ventrículo esquerdo (FEVE) considerada normal, avaliada pelo ecodopplercardiograma através do método área-comprimento.

3. Confirmação angiográfica de DAC bi ou triarterial, com documentação de obstrução luminal de pelo menos $70 \%$, considerando-se somente ramos coronários principais.

Critérios de não-inclusão:

1. Valvopatias.

2. Aneurisma do ventrículo esquerdo.

3. Disfunção ventricular esquerda.

4. Acidente vascular encefálico prévio.

5. Limitação de análise morfológica para definição de isquemia miocárdica no eletrocardiograma: síndrome de pré-excitação ventricular, bloqueio de ramo esquerdo além de outros distúrbios da condução intraventricular, sobrecarga ventricular esquerda, estimulação cardíaca artificial, etc.

6. Incapacidade física de qualquer natureza.

Escore clínico simplificado ou escore de Hubbard

O escore de Hubbard e cols. ${ }^{10}$ foi validado retrospectivamente em uma população consecutiva e sintomática, submetida à investigação de coronariopatia, através de cintilografia miocárdica e cinecoronariografia em até 6 meses. Através da análise de regressão logística, selecionaram-se 5 variáveis, compondo um escore de 5 pontos que fornecia estimativas de coronariopatia severa, demonstrando que a gravidade da doença aumenta em função da pontuação. 
Tal escore resulta da soma de 1 ponto para cada parâmetro: sexo masculino, história de infarto do miocárdio e/ou ondas $\mathrm{Q}$ no eletrocardiograma, angina típica, diabete, uso de insulina e ainda pontua conforme a faixa etária. Até 39 anos não se adiciona pontos, de 40 a 49 anos soma-se 1 ponto, 50 a 59 anos, 2 pontos, 60 a 69 anos, 3 pontos, 70 a 79 anos, 4 pontos e $\geq 80$ anos, 5 pontos.

O escore varia de zero a 10 pontos, estimando a probabilidade de coronariopatia em 3 grupos: alta $(>5$ pontos), intermediária (igual a 5 pontos) e baixa ( $<5$ pontos).

\section{Desenvolvimento do novo escore}

O novo escore foi estruturado a partir da somatória simples das variáveis do escore de Hubbard e cols. ${ }^{10}$, incorporando também o resultado do TE. Quando o TE resultava positivo, adicionou-se 1 ponto. TE negativo não determinou pontuação adicional. Assim, a pontuação total do novo escore variou de 0 a 11 pontos conforme ilustra a tabela 1 . O valor de corte considerado para alto risco de eventos e óbito foi de 6 pontos, após análise da curva de sobrevida.

Foi considerado teste positivo a presença de depressão do segmento $\mathrm{ST} \geq 1 \mathrm{~mm}$, de morfologia horizontal ou descendente, durante ou após o exercício, sendo a magnitude

Tabela 1 - Variáveis do novo escore com a pontuação correspondente

\begin{tabular}{ll}
\hline Variáveis & Pontuação \\
\hline Sexo & \\
\hline Feminino & 0 \\
\hline Masculino & 1 \\
\hline História de infarto do miocárdio & \\
\hline Não & 0 \\
\hline Sim & 1 \\
\hline Angina pectoris & \\
\hline Atípica & 0 \\
\hline Típica & 1 \\
\hline Diabete melito & \\
\hline Ausente & 0 \\
\hline Não insulino-dependente & 1 \\
\hline Insulino-dependente & 2 \\
\hline Faixa etária & \\
\hline$<40$ anos & 0 \\
\hline 40 a 49 anos & 1 \\
\hline 50 a 59 anos & 2 \\
\hline 60 a 69 anos & 3 \\
\hline 70 a 79 anos & 4 \\
\hline Igual ou superior a 80 anos & 5 \\
\hline Teste ergométrico & 1 \\
\hline Negativo & \\
\hline Positivo & \\
\hline & \\
\hline & \\
\hline & \\
\hline & \\
\hline & \\
\hline
\end{tabular}

do desnível aferida a $80 \mathrm{~ms}$ do ponto J; ou presença de elevação do segmento $\mathrm{ST} \geq 1,0 \mathrm{~mm}$ em derivações sem ondas Q patológicas, seguindo as recomendações das diretrizes sobre $\mathrm{TE}^{1,22}$.

O resultado positivo foi considerado como a prova documental da isquemia miocárdica, adicionando um ponto no novo escore prognóstico. $\mathrm{O}$ resultado negativo foi considerado como ausência de documentação de isquemia miocárdica e sem valor prognóstico adicional no escore.

\section{Análise estatística}

A associação entre o novo escore e cada um dos desfechos foi analisada pela regressão de $\mathrm{Cox}^{23}$, inclusive para identificar subgrupos de alto risco. A curva de sobrevida cardiovascular foi gerada de acordo com método de Kaplan-Meier ${ }^{24}$ e o teste Log-Rank aplicado para comparar essas curvas de sobrevida. Para todas as análises uma $p<0,05$ foi considerada estatisticamente significante.

\section{Resultados}

Dos 372 pacientes estudados, 156 pacientes tinham história de infarto do miocárdio, 334 apresentavam angina pelo menos classe funcional II, $137(36,8 \%)$ eram diabéticos, sendo $16(0,11 \%)$ usuários regulares de insulina.

Durante o período total de seguimento, observaram-se 29 episódios de infarto do miocárdio não-fatal, sendo 11 no grupo ATC, 6 no grupo RM e 12 no grupo TC, sendo essa diferença entre os grupos considerada não significativa $(p=0,21)$.

Com relação à necessidade de RM após a randomização, observaram-se 06 casos no grupo ATC, 2 casos no grupo RM e 16 casos no grupo TC, sendo essa diferença entre os grupos considerada significante $(p=0,001)$.

A necessidade de ATC após a randomização foi observada em 18 casos no grupo ATC, 03 casos no grupo RM e em 04 casos no grupo TC, sendo essa diferença entre os grupos considerada significante $(p=0,001)$.

Foram observados 36 óbitos durante o seguimento, sendo 10 no grupo ATC, 15 no grupo RM e em 11 casos no grupo $T C,(p=0,61)$. A incidência de óbito após a randomização foi observada em 10 pacientes com escore $<6$ pontos e em 26 pacientes com escore $\geq 6$ pontos ( $p=0,07$ ).

O total de eventos combinados foi de 93 , com a seguinte distribuição entre os grupos: 37 no grupo ATC, 23 no grupo RM e 33 no grupo TC, com diferença marginalmente significante $(p=0,058)$. A incidência de eventos combinados após a randomização foi observada em 34 pacientes com escore $<6$ pontos e em 59 pacientes com escore $\geq 6$ pontos $(p=0,22)$.

Quando se avaliou a idade, para os diferentes grupos, não se observou diferença significativa ( $p=0,73$ ), com idade média de $59,75 \pm 9,5$ anos para o grupo ATC (127 pacientes), $59,97 \pm 8,4$ anos para o grupo RM (130 pacientes), 59,08 \pm 9,3 anos para o grupo TC (115 pacientes).

Com relação ao sexo, um escore inferior a 06 pontos foi observado em 97 homens e em 59 mulheres. Escore $\geq 06$ pontos foi observado em 169 homens e em 47 mulheres. 
Storti e cols.

Novo escore prognóstico para angina estável

\section{Artigo Original}

A necessidade de RM após a randomização foi observada em 8 pacientes com escore $<6$ pontos e em 16 pacientes com escore $\geq 6$ pontos ( $p=0,37$ ).

A necessidade de ATC após a randomização foi observada em 12 pacientes com escore $<6$ pontos e em 13 pacientes com escore $\geq 6$ pontos ( $p=0,52$ ).

A análise pela curva de sobrevida demonstrou que houve diferença marginalmente significante na incidência de eventos combinados para os pacientes com escore de Hubbard $<5$ ou $\geq 5$ pontos ( $p=0,062$ ), (Figura 1 ).

Quando se avaliou a incidência de eventos combinados para o novo escore, houve diferença estatisticamente significante $(p=0,02)$ entre os pacientes com escore < $6 \mathrm{e} \geq 6$ pontos, conforme ilustram as respectivas curvas comparativas de sobrevida da figura 2.

A incidência de óbito cardiovascular foi maior nos pacientes com escore $\geq 5$ pontos pelo escore de Hubbard $(p=0,015)$, figura 3. A diferença na incidência de óbito foi mais significante entre os pacientes com escore $<6$ e $\geq 6$ pontos, com $p=0,004$, figura 4 .

Comparando os dois escores, observou-se que 31 pacientes foram classificados com alto risco pelo escore de Hubbard, mas, considerados como baixo risco pelo novo escore. Nenhum indivíduo de baixo risco pelo escore de Hubbard foi classificado como de alto risco no novo escore, conforme ilustra a tabela 2. A diferença da classificação de risco entre os escores foi considerada estatisticamente significante ( $p$ $=0,001)$. Do total de pacientes analisados, $247(66,4 \%)$ apresentaram escore de Hubbard $\geq 5$ pontos e $216(58 \%) \geq$ 6 pontos, como demonstra a tabela 2 . O valor de corte $\geq 5$ ou $\geq 6$ pontos identificou indivíduos de maior risco de óbito, com $p=0,015$ e $p=0,004$, respectivamente.

Em relação ao desfecho primário, a análise da curva de sobrevida não demonstrou diferença entre os três grupos de tratamento, figura 5 .

Em relação à incidência de óbito e escore de Hubbard $\geq$ 5, observaram-se 15 óbitos no grupo ATC, 12 no grupo RM e 10 no grupo TC, $(p=0,59)$, enquanto que com escore < 5 pontos, observamos 1 óbito no grupo ATC, 5 no grupo RM e 3 no grupo TC ( $p=0,176)$.

Em relação à incidência de óbito e novo escore $\geq 6$, observaram-se 11 óbitos no grupo ATC, 7 no grupo RM e 6 no grupo TC, $(p=0,4)$. Na presença de novo escore $<6$ pontos evidenciaram-se 1 óbito no grupo ATC, 6 no grupo RM e 3 no grupo TC $(p=0,163)$.

Quanto à ocorrência de eventos combinados nos pacientes com escore de Hubbard $\geq 5$ pontos, observaram-se 33 eventos no grupo ATC, 13 no grupo RM e 23 no grupo TC, com uma incidência de eventos significantemente reduzida no grupo $R M(p<0,001)$. A análise da incidência de eventos combinados nos pacientes com escore de Hubbard $<5$ pontos, mostrou 1 evento no grupo ATC, 5 eventos no grupo RM e 3 no grupo TC ( $p=0,24)$.

Ao analisar a incidência de eventos combinados nos pacientes com novo escore $\geq 6$ pontos, observaram-se 24 eventos no grupo ATC, 8 no grupo RM e 12 no grupo TC $(p=0,001)$. Nos

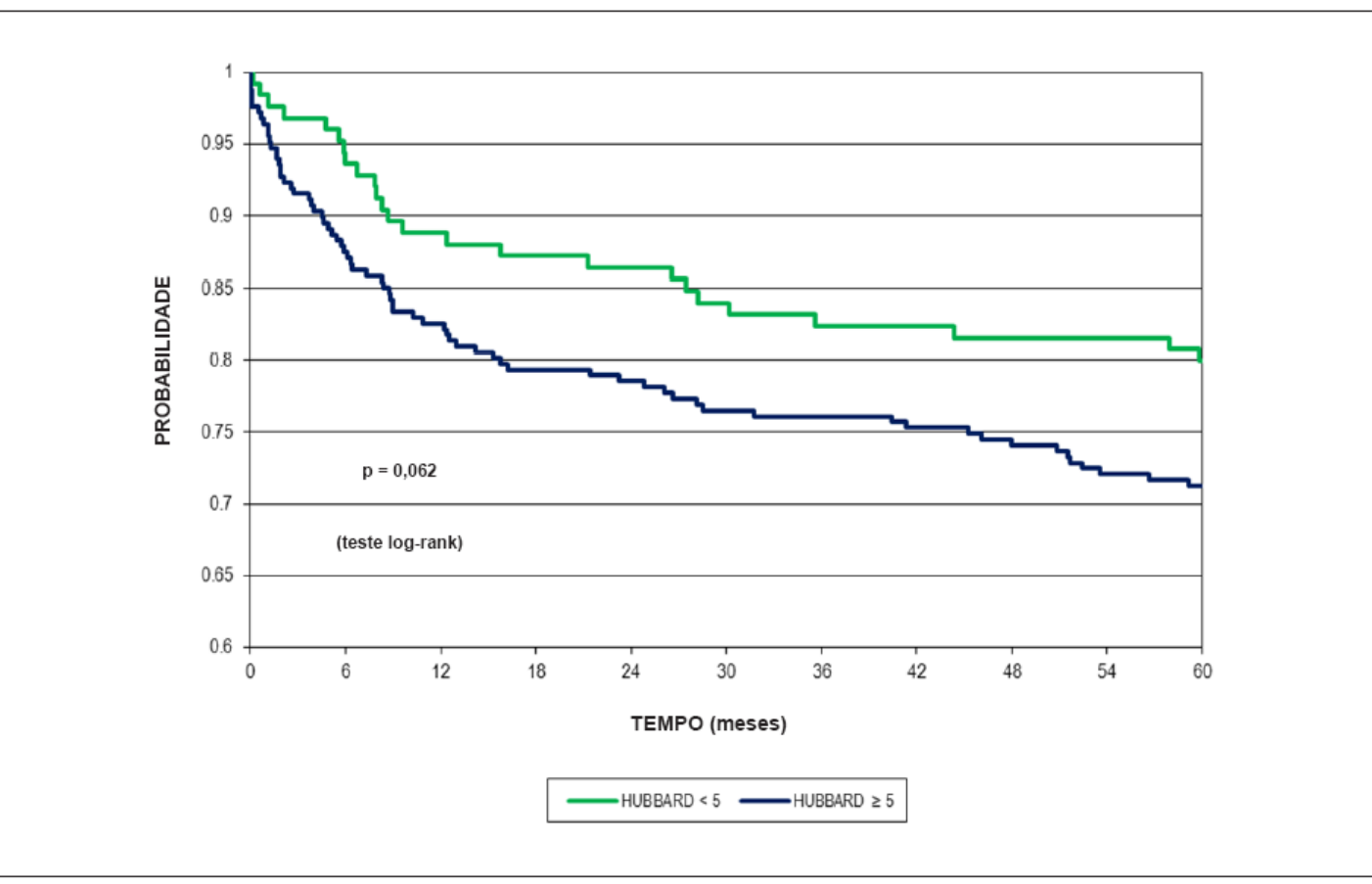

Fig. 1 - Comparação da taxa de eventos combinados entre os pacientes com escore de Hubbard $<5$ e $\geq 5$ pontos. 
Artigo Original

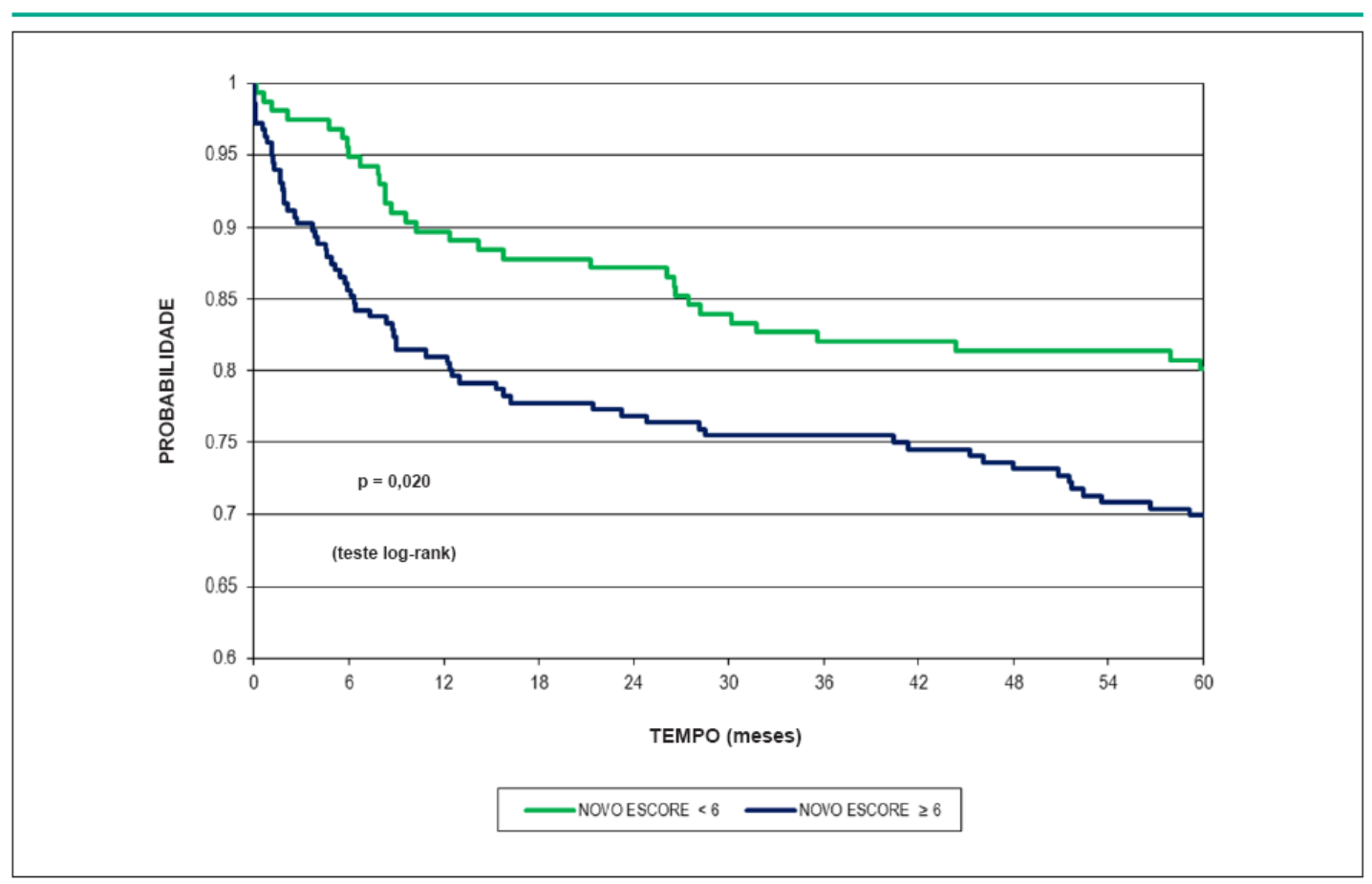

Fig. 2 - Comparação da taxa de eventos combinados entre os pacientes com o novo escore $<6 \mathrm{e} \geq 6$ pontos.

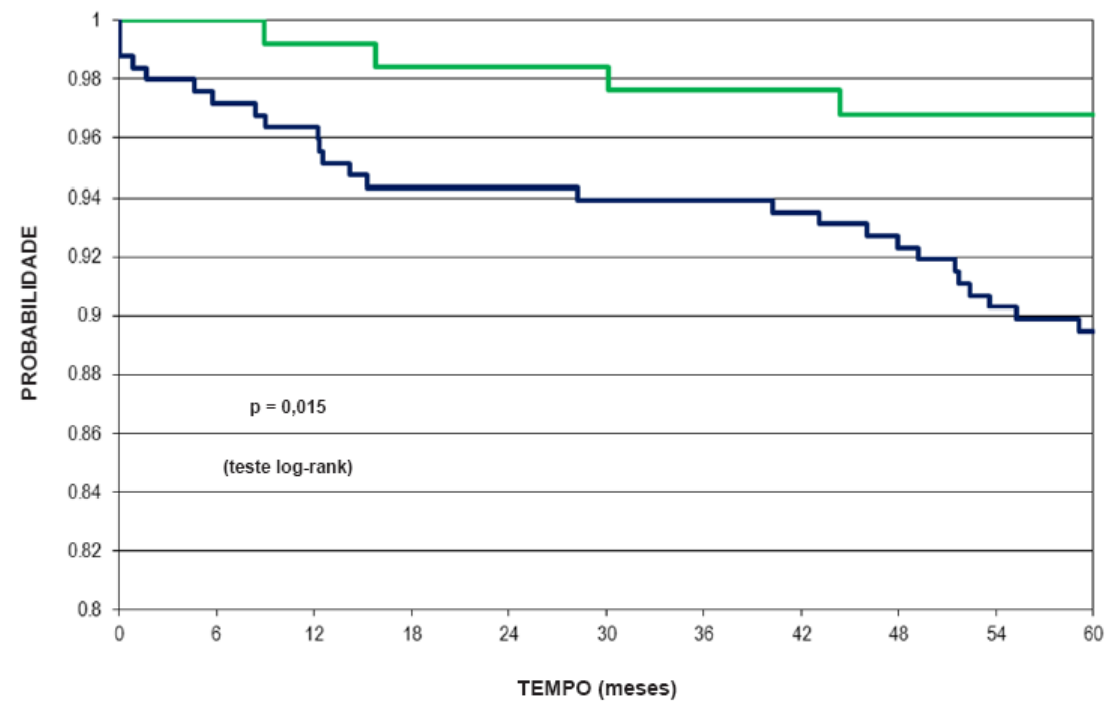

HUBBARD $<5-$ HUBBARD $\geq 5$

Fig. 3 - Comparação entre a taxa de óbito cardiovascular nos pacientes com escore de Hubbard < 5 pontos e $\geq 5$ pontos. 
Storti e cols.

Novo escore prognóstico para angina estável

\section{Artigo Original}

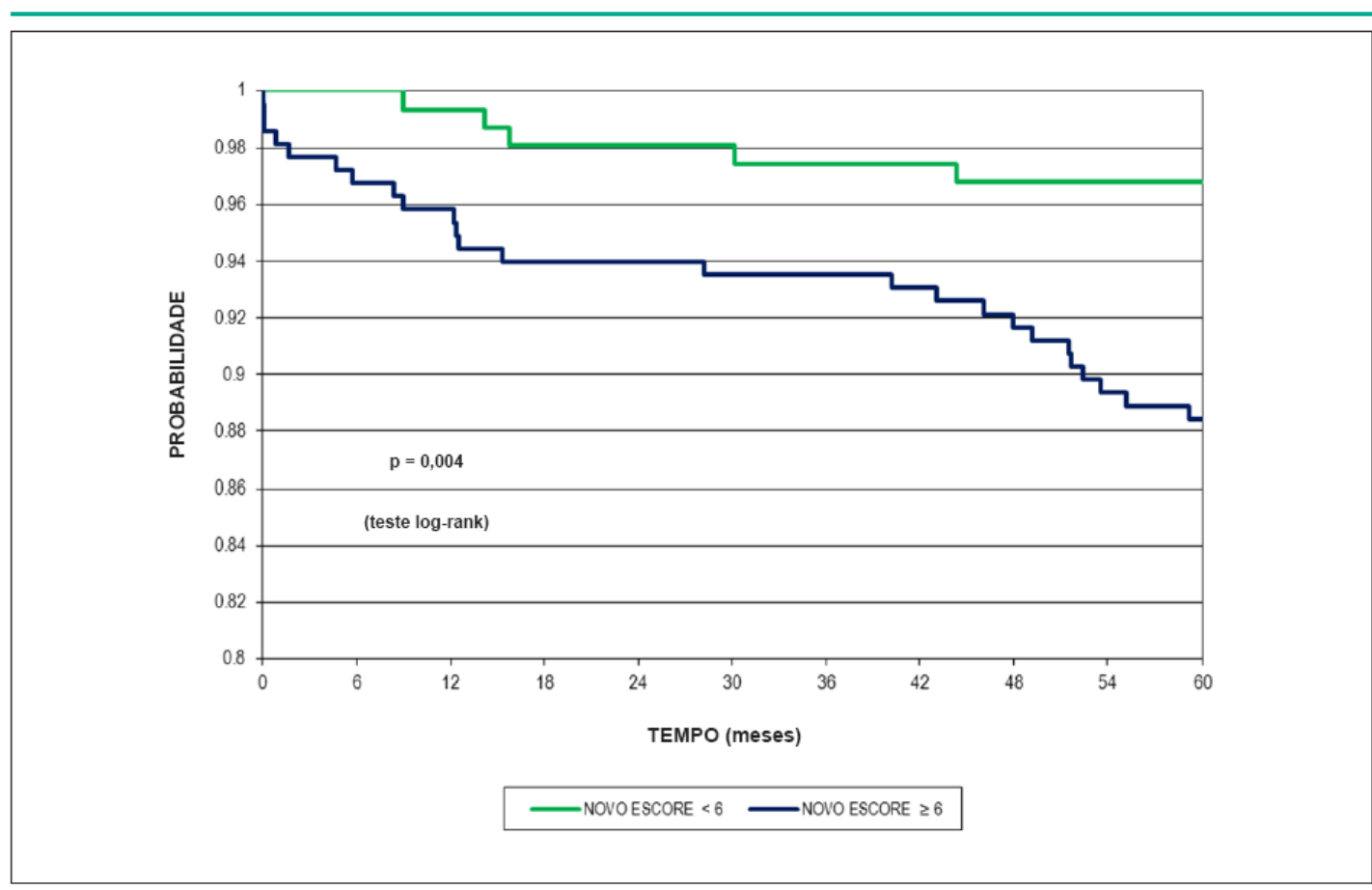

Fig. 4 - Comparação entre a taxa de óbito cardiovascular nos pacientes com novo escore $<6$ pontos e $\geq 6$ pontos.

Tabela 2 - Comparação entre os escores. Distribuição dos pacientes conforme pontuação nos dois escores

\begin{tabular}{lcc}
\hline Pontuação & $<5$ pontos & $\geq 5$ pontos \\
\hline$<6$ pontos & 125 & 31 \\
\hline$\geq 6$ pontos & 0 & 216 \\
\hline Total & 125 & 247 \\
\hline
\end{tabular}

pacientes com escore $<6$ pontos observamos 9 eventos no grupo ATC, 5 no grupo RM e 9 no grupo TC $(p=0,334)$.

\section{Discussão}

A avaliação prognóstica é um componente crucial da avaliação clínica da DAC. Embora os pacientes com angina estável apresentem baixa mortalidade ${ }^{25-27}$, o risco de infarto do miocárdio, a necessidade de intervenções e os sintomas impactam a evolução clínica de maneira representativa.

Vários escores foram desenvolvidos para estratificação de DAC adotando-se parâmetros clínicos e do TE ou combinados $^{28,29}$, contudo, escores prognósticos no portador de angina estável são escassos ${ }^{30}$.

A proposta desse estudo foi desenvolver um índice para estratificação de risco do coronariopata estável multiarterial através de um método simples e acessível, contrastando com a ampla gama de procedimentos de alto custo disponíveis.
Em nossa casuística, a idade média de 59,5 anos, determinou um maior valor inicial do escore. Assim, nossa amostra foi representada por indivíduos com uma faixa etária maior, portanto, com um perfil de maior risco. O predomínio masculino na amostra estudada não impactou a interpretação dos resultados devido a documentação de DAC multiarterial em ambos os sexos.

A maioria dos homens $(63,29 \%)$ apresentou escore $\geq 6$ pontos, enquanto na maioria das mulheres foi observado um escore $<6$ pontos. A pontuação maior para os homens pode estar relacionada ao fato de que o sexo masculino já define uma pontuação adicional. Além disso, infarto do miocárdio é mais comum em homens, porém as mulheres apresentam um prognóstico pior, devido a maior taxa de óbito e reinfarto ${ }^{31}$. Quanto a dor precordial, embora ela seja mais frequente nas mulheres, a prevalência de DAC significante é menor, determinando um valor preditivo menor para os testes não-invasivos ${ }^{32,33}$.

A análise prognóstica não considerou a diferença entre os padrões angiográficos bi ou triarterial devido a um baixo número de desfechos no período de seguimento.

A taxa de óbitos (10,33\%) em nossa casuística foi superior à mortalidade geral de pacientes com angina estável, que está ao redor de $1 \%$ ao ano segundo dados da diretriz sobre angina estável ${ }^{33}$. Isto pode ser explicado pela presença de um maior número de pacientes de alto risco em nosso estudo, com maior prevalência de multiarteriais e de diabéticos, apesar da função ventricular esquerda preservada. 


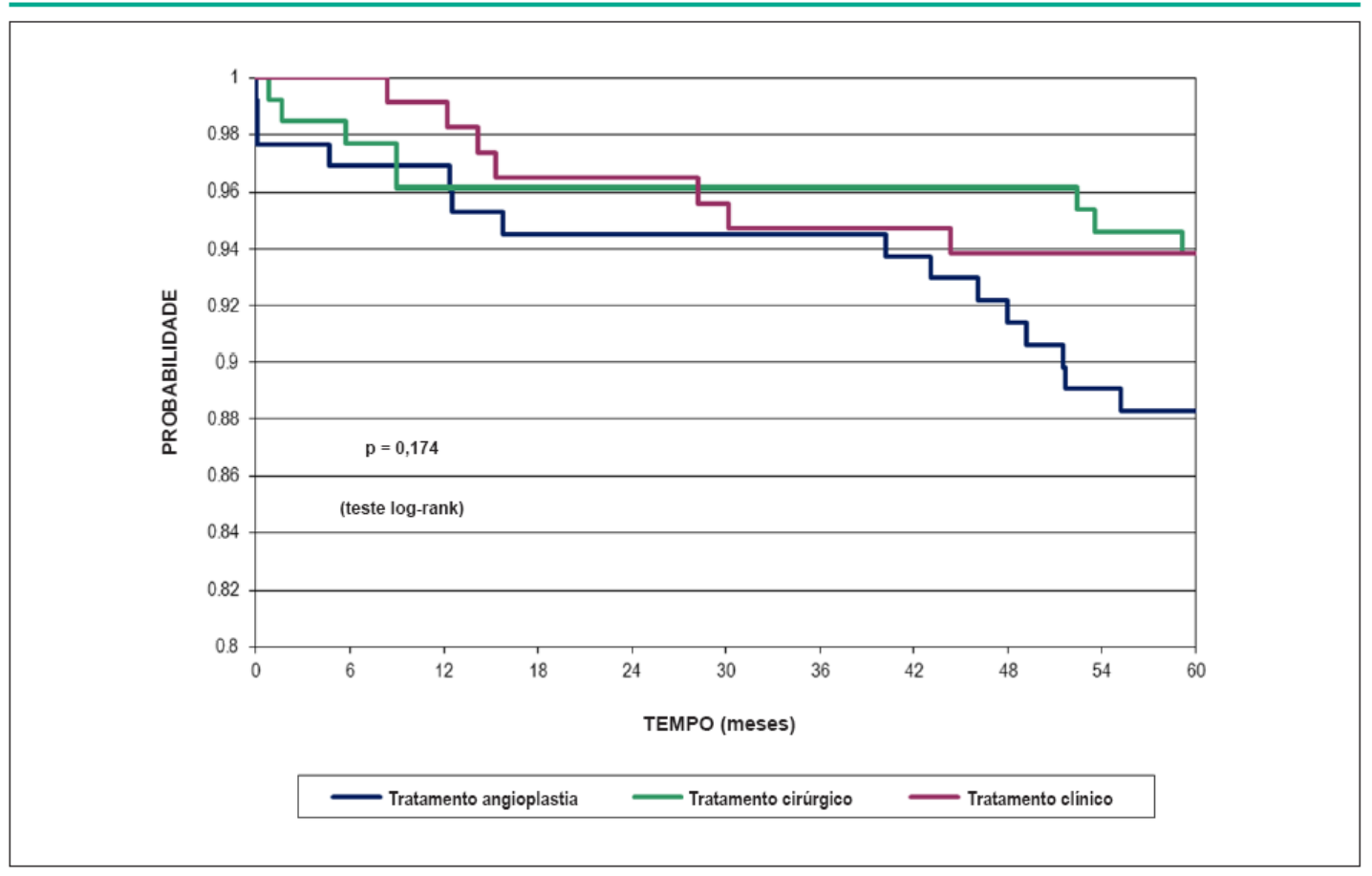

Fig. 5 - Análise da curva de sobrevida em relação ao desfecho primário comparando os três grupos de tratamento.

A incidência de eventos combinados e a necessidade de re-intervenção com angioplastia após a randomização foi maior no grupo ATC. Provavelmente, isto está relacionado a uma maior taxa de reestenose, já que uma parte representativa de nossa amostra possui diabete. Taxas maiores de reestenose são comumente encontradas nos diabéticos ${ }^{34}$.

A alta taxa de diabéticos (36,8\%) determinou também uma maior pontuação inicial no escore. Compatível com o fato de que os portadores de diabete possuem maior incidência de coronariopatia grave. Está bem definido que o diabete é um fator de risco maior para eventos coronarianos ${ }^{35}$. O diabete tipo 2 é de particular importância, pois, é mais comum e ocorre frequentemente em idosos, quando múltiplos fatores de risco coexistem.

Em relação ao $T E$, os diabéticos representam um grupo particularizado: há uma maior incidência de hipertensão arterial, vasculopatia periférica, neuropatia periférica, obesidade e menor capacidade funcional. Além disso, estão mais expostos ao uso de medicamentos que limitam a frequência cardíaca. Assim, quando múltiplos fatores de risco coexistem, há limitação para que se atinja um baixo risco no escore de Duke. Adicionalmente, o nível de trabalho alcançado pode não ser suficiente para a documentação de isquemia miocárdica, mesmo com eventual DAC significante.

O escore de Hubbard foi selecionado inicialmente para compor o novo escore, pois, contêm variáveis de fácil avaliação. O número de variáveis é pequeno, a somatória dos pontos é simplificada e de fácil interpretação, possuindo correlação linear entre o resultado e o prognóstico. Além disso, pode identificar indivíduos de alto risco, mesmo quando classificados em baixo risco pelo escore de Duke ${ }^{36}$. Contudo, ele possui limitações, como a análise exclusiva de variáveis clínicas, não considerando uma prova documental de isquemia miocárdica que comprovadamente fornece informação prognóstica adicional ${ }^{37}$.

Ao acrescentar essa variável na análise, 31 pacientes foram classificados como baixo risco pelo novo escore, pois apresentavam teste ergométrico negativo. Assim, o escore de Hubbard pode ter superestimado o grupo de maior risco na população estudada.

No TE, embora outras variáveis como capacidade funcional, arritmias, respostas cronotrópica e inotrópica, sejam consideradas de maior valor preditivo do que a depressão do segmento ST, existe um vício de interpretação dos vários estudos. Não se considerou que na prática clínica um TE positivo acaba implicando na indicação de estudo cineangiocoronariográfico e, consequentemente, de tratamento farmacológico ou procedimentos de revascularização miocárdica (cirúrgica ou percutânea). Tais intervenções terapêuticas determinam uma alteração na evolução natural da doença coronariana que impacta no valor prognóstico do marcador eletrocardiográfico de isquemia miocárdica.

A análise prognóstica do novo escore não incorporou essas inúmeras variáveis específicas do $T E$, adotando somente a presença de documentação eletrocardiográfica 
Storti e cols.

Novo escore prognóstico para angina estável

\section{Artigo Original}

de isquemia miocárdica, pois o objetivo foi aplicar um sistema prático, de fácil memorização e interpretação, para que ele seja mais amplamente aceito tanto pelo clínico quanto pelo especialista.

Com o uso de escores prognósticos simplificados aplicados em associação ao TE podemos estratificar de forma mais acurada o coronariopata estável, reduzindo a taxa de solicitação de procedimentos de alta complexidade.

Escores melhoram a acurácia prognóstica do TE, diminuem vícios de interpretação e organizam as diversas informações clínicas, determinando uma redução na subjetividade e na variabilidade da estratificação de risco. Particularmente, o escore proposto por este estudo demonstrou seu valor prognóstico de forma abrangente, através de uma sistemática simples e organizada.

\section{Referências}

1. Gibbons RJ, Balady GJ, Bricker JT, Chaitman BR, Fletcher CF, Froelicher VF, Mark DB, et al. American College of Cardiology/American Heart Association Task Force on Practice Guidelines (Committee to Update the 1997 Exercis Testing Cuidelines). ACC/AHA 2002 guideline update for exercise testing: summary article: a report of the American College of Cardiology/American Heart Association Task Force on Practice Cuidelines (Committee to Update the 1997 Exercise Testing Cuidelines). Circulation. 2002;106(14):1883-92.

2. Diamond CA, Forrester JS. Analysis of probability as an aid in the clinica diagnosis of coronary-artery disease. N Eng| J Med. 1979;300(24):1350-8.

3. Morise AP, Jalisi F. Evaluation of pretest and exercise test scores to assess all-cause mortality in unselected patients presenting for exercise testing with symptoms of suspected coronary artery disease. J Am Coll Cardiol. 2003;42(5):842-50.

4. Ashley EA, Myers J, Froelicher V. Exercise testing in clinical medicine. Lancet. 2000;356(9241):1592-7.

5. Froelicher V, Shetler K, Ashley E. Better decisions through science: exercise testing scores. Prog Cardiovasc Dis. 2002;44(5):395-414.

6. Morise AP, Detrano R, Bobbio M, Diamond CA. Development and validation of a logistic regression-derived algorithm for estimating the incrementa probability of coronary artery disease before and after exercise testing. I Am Coll Cardiol. 1992;20(5):1187-96.

7. Mark DB, Mark AH, Harrell FE, Lee KL, Califf RM, Pryor DB. Exercise treadmil score for predicting prognosis in coronary artery disease. Ann Intern Med. 1987;106(6):793-800.

8. Raxwal V, Shetler K, Morise A, Do D, Myers J, Atwood JE, et al. Simple treadmil score to diagnose coronary disease. Chest. 2001;119(6):1933-40.

9. Do D, West JA, Morise A, Atwood E, Froelicher V. A consensus approach to diagnosing coronary artery disease based on clinical and exercise test data. Chest. 1997;111(6): 1742-9.

10. Hubbard BL, Gibbons RJ, Lapeyre AC 3rd, Zinsmeister AR, Clements IP. Identification of severe coronary artery disease using simple clinical parameters. Arch Intern Med. 1992;152(2):309-12

11. Morrow K, Morris CK, Froelicher VF, Hideg A, Hunter D, Johnson E, et al. Prediction of cardiovascular death in men undergoing noninvasive evaluation for coronary artery disease. Ann Intern Med. 1993;118(9):689-95.

12. Detrano R, Bobbio M, Olson $H$, Shandling A, Ellestad MH, Alegria E, et al. Computer probability estimates of angiographic coronary artery disease: transportability and comparison with cardiologist's estimates. Comput Biomed Res, 1992:25(5): 468-85.

13. Lu ZY, Haus S. Evaluation of exercise-induced QRS amplitude changes (Athens score) and their clinical value. J Tongji Med Univ. 1993;13(3): 177-82.

\section{Conclusões}

Este novo escore é um método objetivo e simples para estratificação de risco do coronariopata estável.

\section{Potencial Conflito de Interesses}

Declaro não haver conflito de interesses pertinentes.

Fontes de Financiamento

O presente estudo não teve fontes de financiamento externas.

\section{Vinculação Acadêmica}

Este artigo é parte de tese de doutorado de Fernanda Coutinho Storti pelo InCor - HCFMUSP.

14. Villella M, Villella A, Santoro L, Santoro E, Franzosi MC, Maggioni AP, et al. Ergometric score systems after myocardial infarction: prognostic performance of the Duke Treadmill Score, Veterans Administration Medical Center Score, and of a novel score system, CISSI-2 Index, in a cohort of survivors of acute myocardial infarction. Am Heart J. 2003;145(3):475-83.

15. Koide $Y$, Yotsukura $M$, Yoshino $H$, Ishikawa $K$. A new coronary artery disease index of treadmill exercise electrocardiograms based on the step-up diagnostic method. Am J Cardiol. 2001;15;87(2):142-7.

16. Hollenberg M, Budge WR, Wisneski JA, Gertz EW. Treadmill score quantifies electrocardiographic response to exercise and improves test accuracy and reproducibility. Circulation. 1980;61(2):276-85.

17. Mark DB, Shaw L, Harrell FE Jr, Hlatky MA, Lee KL, Bengtson JR, et al. Prognostic value of a treadmill exercise score in outpatients with suspected coronary artery disease. N EngIJ Med. 1991;325(12):849-53.

18. Ho KT, Miller TD, Hodge DO, Bailey KR, Gibbons RJ. Use of a simple clinical score to predict prognosis of patients with normal or mildly abnormal restin electrocardiographic findings undergoing evaluation for coronary artery disease. Mayo Clin Proc. 2002;77(6):515-21.

19. Soares PR, Hueb WA, Lemos PA, Lopes N, Martinez EE, Cesar LA, et al. Coronary revascularization (surgical or percutaneous) decreases mortality after the first year in diabetic subjects but not in nondiabetic subjects with multivessel disease: an analysis from the Medicine, Angioplasty, or Surth Study (MASS II). Circulation. 2006:114(1 Suppl):1420-4.

20. Hueb WA, Bellotti C, Oliveira SA, Arie S, Albuquerque CP, Jatene AD, et al. The Medicine, Angioplasty or Surgery Study (MASS): a prospective, randomized trial of medical therapy, balloon angioplasty or bypass surgery for single proximal left anterior descending artery stenoses. J Am Coll Cardiol. 1995;26(7):1600-5

21. Bruce RA. Evaluation of functional capacity and exercise tolerance of cardiac patients. Mod Concepts Cardiovasc Dis. 1956;25(4):321-6.

22. Brito FS, Vilas-Boas F, Castro I, Oliveira JÁ, Cuimarães JI, Stein R/ Sociedade Brasileira de Cardiologia. II Diretriz sobre teste ergométrico. Arq Bras Cardiol. 2002;78(supl 2):1-18.

23. Cox DR. Regression models and life-tables. J R Stat Soc Ser B Metodol. 1972;34(2): 187-220

24. Kaplan EL, Meier P. Nonparametric estimation from incomplete observations. Am Stat Soc. 1958:53:457-81.

25. Yusuf S, Sleight P, Pogue J, Bosch J, Davies R, Dagenais C. Effects of an angiotensin-converting-enzyme inhibitor, ramipril, on cardiovascula events in high-risk patients: the heart outcomes prevention evaluation study investigators. N Engl J Med. 2000;342(3):145-53. 
26. Fox KM. Efficacy of perindopril in reduction of cardiovascular events among patients with stable coronary artery disease: randomised, doubleblind, placebo-controlled, multicentre trial (the EUROPA study). Lancet. 2003;362(9386): 782-8.

27. Poole-Wilson PA, Lubsen J, Kirwan BA, van Dalen FJ, Wagener G, Danchin $\mathrm{N}$, et al. Effect of long-acting nifedipine on mortality and cardiovascular morbidity in patients with stable angina requiring treatment (ACTION trial): randomised controlled trial. Lancet. 2004;364(9437):849-57.

28. Pryor DB, Shaw L, Harrell FE Jr, Lee KL, Hlatky MA, Mark DB, et al. Estimating the likelihood of severe coronary artery disease. Am J Med. 1991;90(5):553-62.

29. Yamada H, Do D, Morise A, Atwood JE, Froelicher V. Review of studies using multivariable analysis of clinical and exercise test data to predict angiographic coronary artery disease. Prog Cardiovasc Dis. 1997;39(5):457-81.

30. Prakash M, Myers J, Froelicher VF, Marcus R, Do D, Kalisetti D, et al. Clinical and exercise test predictors of all-cause mortality: results from $>6,000$ consecutive referred male patients. Chest. 2001;120(3): 1003-13.

31. Kannel WB, Sorlie P, McNamara PM. Prognosis after initial myocardial infarction: the Framingham study. Am J Cardiol. 1979;44(1):53-9.
32. Gibbons RJ. Exercise ECG testing with and without radionuclide studies. In Wenger NK, Speroff L, Packard B, eds. Cardiovascular health and disease in women. London: Le Jacq Communications; 1993. p. 73-80.

33. Mansur AP, Armaganijan D, Amino JC, Sousa AC, Simão AF, Brito AX, et al./ Sociedade Brasileira de Cardiologia. Diretriz de doença coronariana crônica angina estável. Arq Bras Cardiol. 2004; 83(supl.2): 7-40.

34. Singh M, Gersh BJ, McClelland RL, Ho KK, Willerson JT, Penny WF, et al. Clinical and angiographic predictors of restenosis after percutaneous coronary intervention: insights from the Prevention of Restenosis With Tranilast and lts Outcomes (PRESTO) trial. Circulation. 2004;109(22):2727-31.

35. Wilson PW, D'Agostino RB, Levy D, Belanger AM, Silbershatz H, Kannel WB. Prediction of coronary heart disease using risk factor categories. Circulation. 1998;97(18): 1837-47.

36. Poornima IC, Miller TD, Christian TF, Hodge DO, Bailey KR, Gibbons RJ. Utility of myocardial perfusion imaging in patients with low-risk treadmill scores. J Am Coll Cardiol. 2004;43(2):194-9.

37. Mora S, Redberg RF, Sharrett AR, Blumenthal RS. Enhanced risk assessment in asymptomatic individuals with exercise testing and Framingham risk scores. Circulation. 2005; 112(11):1566-72. 
REFERÊNCIAS 


\section{REFERÊNCIAS ${ }^{1}$}

Arquivos Brasileiros de Cardiologia. Diretriz de Angina Estável. Arq. Bras. Cardiol. Volume 83, Suplemento II, 2004.

Arquivos Brasileiros de Cardiologia. II Diretriz sobre Teste Ergométrico. Arq Bras Cardiol. 2002;78 Supl II, 1-18.

Ashley EA, Myers J, Froelicher V. Exercise testing in clinical medicine. Lancet. 2000 Nov 4;356(9241):1592-7.

Bruce RA. Evaluation of junctional capacity and exercise tolerance of cardiac patients. Concepts Cardiovasc Dis. 1956;25:321.

Campeau L. Grading of angina pectoris. Circulation. 1976;54:522-3.

Cox DR. Regression models and life-tables. J R Stat Soc,1972;34:187-220.

Detrano $R$, Bobbio $M$, Olson $H$, Shandling A, Ellestad $M H$, Alegria $E$, Martinez-Caro D, Righetti A, Janosi A, Steinbrunn W. Computer probability estimates of angiographic coronary artery disease: transportability and comparison with cardiologist's estimates. Comput Biomed Res. 1992; 25:468-85.

${ }^{1}$ De acordo com:

Adaptado de International Committee of Medical Journals Editors (Vancouver).

Universidade de São Paulo. Faculdade de Medicina. Serviço de Biblioteca e Documentação. Guia de apresentação de dissertações, teses e monografias da FMUSP. Elaborado por Anneliese Carneiro da Cunha, Maria Julia A.L. Freddi, Maria F. Crestana, Marinalva de S. Aragão, Suely C. Cardoso, Valéria Vilhena. 3a ed. São Paulo: Divisão de Biblioteca e Documentação; 2011.

Abreviaturas dos títulos dos periódicos de acordo com List of Journals Indexed in Index Medicus. 
Diamond GA, Forrester JS. Analysis of probability as an aid in the clinical diagnosis of coronary-artery disease. N Engl J Med. 1979;300:1350-8.

Do D, West JA, Morise A, Atwood E, Froelicher V. A consensus approach to diagnosing coronary artery disease based on clinical and exercise test data. Chest. 1997;111(6):1742-9.

Farb A, Virmani R, Atkinson JB, Kolodgie FD. Plaque morphology and pathologic changes in arteries from patients dying after coronary balloon angioplasty. J Am Coll Cardiol. 1990;16:1421-9.

Fox KM. Efficacy of perindopril in reduction of cardiovascular events among patients with stable coronary artery disease: randomised, double-blind, placebo-controlled, multicentre trial (the EUROPA study). Lancet. 2003; 362:782-8.

Froelicher V, Shetler K, Ashley E. Better decisions through science: exercise testing scores. Prog Cardiovasc Dis. 2002 Mar-Apr;44(5):395-414.

Gibbons RJ. Exercise ECG testing with and without radionuclide studies. In Wenger NK, Speroff L, Packard B, eds. Cardiovascular Health and Disease in Women. Greenwich, CT: Le Jacq Communications. 1993;7380.

Gibbons RJ, Balady GJ, Bricker JT, Chaitman BR, Fletcher GF, Froelicher VF, Mark DB, McCallister BD, Mooss AN, O'Reilly MG, Winters WL Jr, Gibbons RJ, Antman EM, Alpert JS, Faxon DP, Fuster V, Gregoratos G, Hiratzka LF, Jacobs AK, Russell RO, Smith SC Jr. American College of Cardiology/American Heart Association Task Force on Practice Guidelines (Committee to Update the 1997 Exercise Testing Guidelines). ACC/AHA 2002 guideline update for exercise testing: summary article: a report of the American College of Cardiology/American Heart Association Task Force on Practice Guidelines (Committee to Update the 1997 Exercise Testing Guidelines). Circulation. 2002a;106:1883-92. 
Gibbons RJ, Balady GJ, Bricker JT, Chaitman BR, Fletcher GF, Froelicher VF, Mark DB, McCallister BD, Mooss AN, O'Reilly MG, Winters WL, Gibbons RJ, Antman EM, Alpert JS, Faxon DP, Fuster V, Gregoratos G, Hiratzka LF, Jacobs AK, Russell RO, Smith SC;. ACC/AHA 2002 guideline update for exercise testing. A report of the American College of Cardiology/American Heart Association Task Force on Practice Guidelines. J Am Coll Cardiol. 2002b;40(8):1531-40.

Ho KT, Miller TD, Hodge DO, Bailey KR, Gibbons RJ. Use of a simple clinical score to predict prognosis of patients with normal or mildly abnormal resting electrocardiographic findings undergoing evaluation for coronary artery disease. Mayo Clin Proc. 2002;77(6):515-21.

Hollenberg M, Budge WR, Wisneski JA, Gertz EW. Treadmill score quantifies electrocardiographic response to exercise and improves test accuracy and reproducibility. Circulation. 1980;61(2):276-85.

Hubbard BL, Gibbons RJ, Lapeyre AC 3rd, Zinsmeister AR, Clements IP. Identification of severe coronary artery disease using simple clinical parameters. Arch Intern Med. 1992; 152:309-12.

Hueb WA, Bellotti G, Oliveira SA, Arie S, Albuquerque CP, Jatene AD, Pileggi F. The Medicine, Angioplasty or Surgery Study (MASS): a prospective, randomized trial of medical therapy, balloon angioplasty or bypass surgery for single proximal left anterior descending artery stenosis. J Am Coll Cardiol. 1995;26:1600-5.

Kannel WB, Sorlie P, McNamara PM. Prognosis after initial myocardial infarction: the Framingham study. Am J Cardiol. 1979 Jul;44(1):53-9.

Kaplan EL, Meier P. Nonparametric estimation from incomplete observations. Am Stat Soc. 1958;53:457-481. 
Karvonen JJ, Kentala E, Mustala O - The effects of training on the heart rate, a longitudinal study. Ann Med Exp Biol Fenn. 1957;35:307.

Kwok JM, Miller TD, Hodge DO, Gibbons RJ. Prognostic value of the Duke treadmill score in the elderly. J Am Coll Cardiol. 2002;39(9):1475-81.

Kastrati A, Schömig A, Elezi S, Schülen H, Dirschinger J, Hadamitzky Mea. Predictive factors of restenosis after coronary stent placement. J Am Coll Cardiol. 1987;9:834-48.

Koide Y, Yotsukura M, Yoshino H, Ishikawa K. A new coronary artery disease index of treadmill exercise electrocardiograms based on the stepup diagnostic method. Am J Cardiol. 2001;15;87(2):142-7.

Lloyd CE, Kuller LH, Ellis D, Becker DJ, Wing RR, Orchard TJ. Coronary artery disease in IDDM: gender differences in risk factors but not risk. Arterioscler Thromb Vasc Biol. 1996;16:720-726.

Lu ZY, Haus S. Evaluation of exercise-induced QRS amplitude changes (Athens score) and their clinical value. J Tongji Med Univ. 1993;13(3):17782.

Mark DB, Mark AH, Harrell FE, Lee KL, Califf RM, Pryor DB. Exercise Treadmill Score for Predicting Prognosis in Coronary Artery Disease. Ann Intern Med. Volume 106, pages 793-800. 1987.

Mark DB, Shaw L, Harrell FE Jr, Hlatky MA, Lee KL, Bengtson JR, McCants CB, Califf RM, Pryor DB. Prognostic value of a treadmill exercise score in outpatients with suspected coronary artery disease. $N$ Engl $J$ Med. $1991 ; 325(12): 849-53$. 
Morise AP, Detrano R, Bobbio M, Diamond GA. Development and validation of a logistic regression-derived algorithm for estimating the incremental probability of coronary artery disease before and after exercise testing. $J$ Am Coll Cardiol. 1992 Nov 1;20(5):1187-96.

Morise AP, Jalisi F. Evaluation of pretest and exercise test scores to assess all-cause mortality in unselected patients presenting for exercise testing with symptoms of suspected coronary artery disease. J Am Coll Cardiol. 2003;842-50.

Morrow K, Morris CK, Froelicher VF, Hideg A, Hunter D, Johnson E, Kawaguchi T, Lehmann K, Ribisl PM, Thomas R, Ueshima K, Froelicher E, Wallis J. Prediction of cardiovascular death in men undergoing noninvasive evaluation for coronary artery disease. Ann Intern Med. 1993; 118:689-95.

Poole-Wilson PA, Lubsen J, Kirwan BA, van Dalen FJ, Wagener G, Danchin $\mathrm{N}$, Just H, Fox KA, Pocock SJ, Clayton TC, Motro M, Parker JD, Bourassa MG, Dart AM, Hildebrandt P, Hjalmarson A, Kragten JA, Molhoek GP, Otterstad JE, Seabra-Gomes R, Soler-Soler J, Weber S. Effect of longacting nifedipine on mortality and cardiovascular morbidity in patients with stable angina requiring treatment (ACTION trial): randomised controlled trial. Lancet. 2004; 364:849-57.

Poornima IG, Miller TD, Christian TF, Hodge DO, Bailey KR, Gibbons RJ. Utility of myocardial perfusion imaging in patients with low-risk treadmill scores. J Am Coll Cardiol. 2004;43(2):194-9.

Prakash M, Myers J, Froelicher VF, Marcus R, Do D, Kalisetti D, Atwood JE. Clinical and exercise test predictors of all-cause mortality: results from > 6,000 consecutive referred male patients. Chest. 2001;120:1003-13. 
Pryor DB, Shaw L, Harrell FE Jr, Lee KL, Hlatky MA, Mark DB, Muhlbaier LH, Califf RM. Estimating the likelihood of severe coronary artery disease. Am J Med. 1991;90:553-62.

Raxwal V, Shetler K, Morise A, Do D, Myers J, Atwood JE, Froelicher VF. Simple treadmill score to diagnose coronary disease. Chest. 2001 Jun;119(6):1933-40.

Richardson WS, Wilson MC, Guyatt GH, Cook DJ, Nishikawa J. Users' guides to the medical literature: XV. How to use an article about disease probability for differential diagnosis. Evidence-Based Medicine Working Group. JAMA. 1999 Apr 7;281(13):1214-9.

Samia Mora, MD, MHS; Rita F. Redberg, MD, MSc; A. Richey Sharrett, MD, DrPH; Roger S. Blumenthal, MD. Enhanced risk assessment in asymptomatic individuals with exercise testing and Framingham risk scores. Circulation. 2005;112:1566-72.

Singh M, Gersh BJ, McClelland RL, Ho KK, Willerson JT, Penny WF, Holmes DR Jr. Clinical and Angiographic Predictors of Restenosis After Percutaneous Coronary Intervention: Insights From the Prevention of Restenosis With Tranilast and its Outcomes (PRESTO) Trial. Circulation. 2004;109:2727-31.

Soares PR, Hueb WA, Lemos PA, Lopes N, Martinez EE, Cesar LA, Oliveira SA, Ramires JA. Coronary revascularization (surgical or percutaneous) decreases mortality after the first year in diabetic subjects but not in nondiabetic subjects with multivessel disease: an analysis from the Medicine, Angioplasty, or Surgery Study (MASS II). Circulation. 2006;114(1 Suppl):I420-4. 
Stone PH, Muller JE, Hartwell T, York BJ, Rutherford JD, Parker CB, Turi ZG, Strauss HW, Willerson JT, Robertson T, Braunwald E, Jaffe AS, and the MILIS Study Group. The effect of diabetes mellitus on prognosis and serial left ventricular function after acute myocardial infarction: contribution of both coronary disease and diastolic left ventricular dysfunction to the adverse prognosis: the MILIS Study Group. J Am Coll Cardiol. 1989;14:49-57.

Storti FC, Moffa PJ, Uchida AH, Hueb WA, César LAM, Ferreira BMA, Camargo Jr PA de, Chalela WA. Avaliação prognóstica da doença coronária estável através de um novo escore. Arq Bras Cardiol. 2011;96(5):411-9.

Villella M, Villella A, Santoro L, Santoro E, Franzosi MG, Maggioni AP, Duke Treadmill Score; Veterans Administration Medical Center Score; GISSI-2 Investigators. Ergometric score systems after myocardial infarction: prognostic performance of the Duke Treadmill Score, Veterans Administration Medical Center Score, and of a novel score system, GISSI2 Index, in a cohort of survivors of acute myocardial infarction. Am Heart J. 2003;145(3):475-83.

Wilson PW. Diabetes mellitus and coronary heart disease. Am J Kidney Dis. 1998;32:S89-S100.

Wilson PW, D'Agostino RB, Levy D, Belanger AM, Silbershatz H, Kannel WB. Prediction of coronary heart disease using risk factor categories. Circulation. 1998;97:1837-47.

Wu EB, Hodson F, Chambers JB. A simple score for predicting coronary artery disease in patients with chest pain. QJM. 2005;98(11):803-11. 
Yamada H, Do D, Morise A, Atwood JE, Froelicher V. Review of studies using multivariable analysis of clinical and exercise test data to predict angiographic coronary artery disease. Prog Cardiovasc Dis 1997;39:45781.

Yusuf S, Sleight P, Pogue J, Bosch J, Davies R, Dagenais G. Effects of an angiotensin-converting-enzyme inhibitor, ramipril, on cardiovascular events in high-risk patients. The heart outcomes prevention evaluation study investigators. N Engl J Med. 2000;342:145-53. 
APÊNDICES 


\section{APÊNDICE 1 \\ CARTA DA COMISSÃO DE ÉTICA PARA ANÁLISE DE PROJETOS DE PESQUISA}

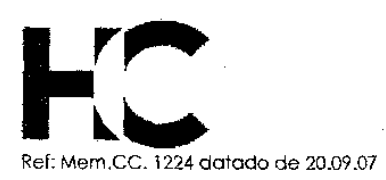

A

Comissāo Científica do InCor

O Presidente da Comissão de Ética para Análise de Projetos de Pesquisa - CAPPesa da Diretoria Clínica do Hospital das Clínicas e da Faculdade de Medicina da Universidade de São Paulo, em 27.09.07, tomou conhecimento que o Protocolo de Pesquisa $n^{\circ}$ 264/04, intifulado: “ESTUdO COMPARATIVO ENTRE OS TRATAMENTOS: MÉdICO. ANGIOPLASTIA OU CIRURGIA EM PORTADORES DE DOENÇA CORONÁRIA MULTIARTERIAL. ESTUDO RANDOMIZADO (MASSII)", contempla o sub-projeto intitulado: "AVALIAÇĀO PROGNÓSTICA DA DOENÇA CORONÁRIA ESTÁVEL ATRAVÉS DE UM ESCORE COMPOSTO COM DADOS CLÍNICOS E O RESULTADO DO TESTE DE ESFORÇO", que será tese de doutorado da Dra. Fernanda Coutinho Storti, tendo como orientador o Prof. Dr. Paulo Jorge Moffa.

Pesquisador Responsável: PROF. DR. WHADY ARMINDO HUEB

CAPPesq, em 27 de setembro de 2007.

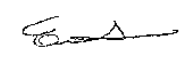

PROF. DR. EDUARDO MASSAD

Presidente da Comissão Ética para Análise de Projetos de Pesquisa

Comissăo de Ética para Análise de Projetos de Pesquisa do HCFMUSP e da FMUSP Diretoria Clínica do Hospital das Clínicas da Faculdade de Medicina da Universidade de Sảo Paulo Rua Ovidio Pires de Campos. 225, $5^{\circ}$ andar - CEP 05430010 - São Pauto - SP
fav. n11 - 2nk9 6497 - a.mail : caooesqencnet.usp.br / secretariacappesq2@hcnet.usp.br 


$$
\text { APÊNDICE } 2
$$

TERMO DE CONSENTIMENTO LIVRE E ESCLARECIDO 


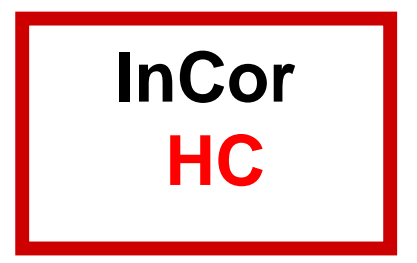

\section{TERMO DE CONSENTIMENTO LIVRE E ESCLARECIDO}

TÍTULO: MASS (The Medicine, Angioplasty and Surgery Study) Estudo prospectivo, comparativo e randomizado entre os tratamentos clinico, cirúrgico ou através da angioplastia em pacientes portadores de doença coronária multiarterial.

NÚMERO DO PROTOCOLO: 946/94/56 InCor - HCFMUSP, Aprovado pela Comissão Científica do Instituto do Coração e pela Comissão de Normas Éticas e Regulamentares sob o n. $.264 / 94$

PATROCINADOR: InCor - HCFMUSP - Fundação E.J. Zerbini

MÉDICO RESPONSÁVEL: Prof. Dr. Whady Armindo Hueb

Este termo de consentimento pode conter palavras técnicas que você talvez não conheça. Por favor, em caso de dúvida pergunte ao seu médico o significado destas palavras.

\section{NATUREZA E OBJETIVO DESTE ESTUDO}

Esta pesquisa foi preparada para avaliar as opções terapêuticas, disponíveis até 0 momento, para pacientes portadores de angina pectoris e doença arterial coronária estáveis, objetivando conhecer seus benefícios e riscos avaliados após acompanhamento de 5 anos e determinar qual é a melhor opção de tratamento neste grupo selecionado de pacientes.

O melhor tratamento das doenças isquêmicas do coração permanece ainda sem definição quando se focaliza aqueles pacientes que apresentam sintomas anginosos estáveis e função ventricular preservada.

As opções de tratamento desta enfermidade incluem cirurgia de revascularização do miocárdio, angioplastia coronária através de catetéres ou tratamento clínico com administração de medicamentos.

Cada opção terapêutica oferece riscos e benefícios para o paciente. 0 tratamento cirúrgico, o mais invasivo, tem a proposta de intervir na própria artéria doente e através de uma derivação, ultrapassar a obstrução arterial.

O risco desta intervenção é inerente ao próprio procedimento e o benefício está relacionado a melhor qualidade de vida que o tratamento oferece. 
A angioplastia coronária é uma alternativa terapêutica moderna que utiliza várias opções, "via cateter", onde se inclui: catéter balão, aterótomo, laser, stent, etc. visando, através destes recursos, desobstruir as artérias e permitir o aumento do fluxo sangüíneo e, com isto, a melhor irrigação do sangue ao miocárdio isquêmico proporcionando o alívio dos sintomas.

Os problemas advindos deste procedimento incluem a repetição da angioplastia em outras oportunidades ou insucesso da intervenção determinando a cirurgia emergencial.

O tratamento clinico, o mais simples, tem a vantagem de não ser invasivo e requer a administração continuada de remédios.

Contudo, o tratamento medicamentoso não provou ainda ser seguro em relação a prevenção do infarto e consequentemente a morte. Desta forma os pacientes que forem designados para este tipo de tratamento terá indicação para outras opções de intervenções caso os sintomas forem se agravando.

Assim, esta pesquisa esta sendo realizada para se estabelecer qual a melhor opção terapêutica para pacientes portadores de angina estável e função ventricular preservada.

\section{EXPLICAÇÕES SOBRE O PROJETO DE PESQUISA}

Esta pesquisa selecionará pacientes portadores de angina estável e função ventricular preservada, e que, requer uma das 3 opções terapêuticas disponíveis: cirurgia, angioplastia ou tratamento clinico.

Após a seleção de pacientes que preencham os critérios já estabelecidos, os pacientes terão indicação de uma das 3 opções terapêuticas disponíveis, já citadas, e, através de randomização será determinado o tipo de tratamento a ser executado.

Se a indicação terapêutica for cirúrgica o paciente será operado pelo médico chefe do serviço cirúrgico, ou se a indicação for para outras formas terapêuticas será executada pelos responsáveis dos respectivos serviços.

Todos os pacientes terão avaliação trimestral e terão oportunidade de mudar a opção terapêutica caso o tratamento não se firmar como satisfatório.

Durante as consultas o paciente fará entrevista com psicólogos, enfermeiros, nutricionista para avaliação pertinentes e que estão incluídos no projeto de pesquisa. Terá também, exames rotineiros previsto neste estudo, os quais estão incluídos cateterismo cardíaco, TE, laboratório. 


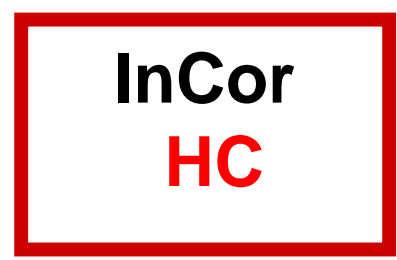

\section{DURAÇÃO DA PESQUISA}

Este estudo terá duração de 5 anos, com acompanhamento médico e demais profissionais incluídos na pesquisa.

Após 5 anos de seguimento será realizado novo cateterismo cardíaco para avaliação da circulação coronária após a intervenção.

O paciente será sempre informado sobre os exames e medicamentos a serem prescritos. Todavia, poderá recusar parte ou todo o procedimento proposto.

\section{POSSIVEIS BENEFÍCIOS DO PROJETO DE PESQUISA}

Por se tratar de terapêuticas múltiplas e conflitantes entre si, objetivamos avaliar todas as opções terapêuticas para tratamento da doença coronária disponíveis até o momento.

Desta forma o resultado final de cada opção terapêutica permanece ainda não estabelecido. Este projeto pretende estabelecer ao final do estudo, qual a melhor opção terapêutica para esta doença.

\section{ALTERNATIVAS}

O paciente não é obrigado a participar, desta pesquisa. Pode, além disso, informar ao médico que pretende, decididamente, uma das 3 opções terapêuticas recusando assim participar desta pesquisa, não perde, além disso, o direito de tratar neste hospital.

\section{CONTATOS}

Caso o paciente apresente problemas médicos relacionados a enfermidade estão disponíveis médicos e telefones do projeto de pesquisa para orientálo.

Médico: Dr. Whady Armindo Hueb / Dr. Paulo Rogério Soares

Telefone: (011) 30695032

Bip Interno: (011) 30695000 código 312 ou 351

\section{CUSTOS}

Não existe custos para participação neste estudo você continuará tendo acesso a exames e consultas rotineiras ou extras previsto no projeto. 


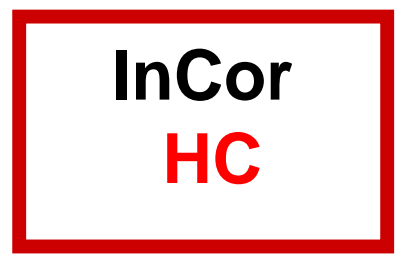

Não será feito nenhum pagamento ao paciente pela participação neste estudo.

\section{CONFIDENCIALIDADE}

As informações deste estudo serão entregues à MASS (The Medicine, Angioplasty and Surgery Study), patrocinador do estudo, que poderá verificar seu prontuário, o que Ihe identificará. $O$ consentimento assinado também poderá ser verificado pelo patrocinador e pelas autoridades locais. Pelo fato da necessidade de liberar informações para estas partes, não garantimos confidencialidade. Os resultados deste estudo podem ser apresentados em reuniões ou publicações entretanto, sua identidade será mantida confidencial nestas reuniões.

\section{PARTICIPAÇÃO VOLUNTÁRIA/RETIRADA}

Sua participação neste estudo é totalmente voluntária. Caso você se recuse a participar deste estudo, você não sofrerá nenhuma penalidade ou perderá qualquer benefício que porventura você tenha com seu médico ou instituição.

Caso você queira participar do estudo, você deverá contatar: MASS (The Medicine, Angioplasty and Surgery Study)

Dr. Whady Hueb /Dr. Paulo Soares através do telefone: (011) 30695032

\section{TÉRMINO}

Sua participação neste estudo pode ser encerrado sob as seguintes circunstâncias:

- Você tenha se mudado para outra área e, portanto, não vai mais se consultar com seu médico;

- Seu médico considera benéfico para sua saúde a sua saída do estudo;

- O patrocinador decida encerrar o estudo;

- As autoridades locais decidam interromper o estudo.

\section{CONSENTIMENTO PARA PARTICIPAR NESTE ESTUDO}

$\mathrm{Li}$ todas as informações mencionadas acima antes de assinar este consentimento. Tive todas as oportunidades de perguntar e obter respostas para minhas dúvidas. Todas as respostas foram satisfatórias. Eu sou voluntário(a) para participar neste estudo. 


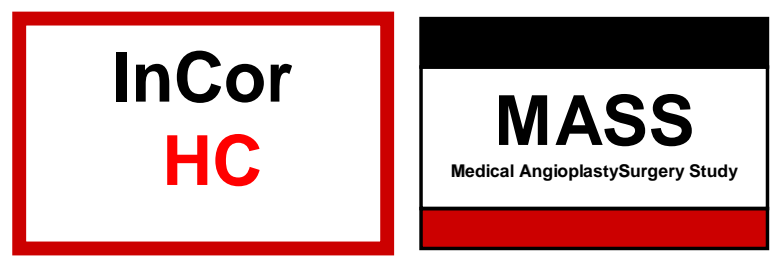

Estou recebendo uma cópia deste consentimento após ter sido assinado. Autorizo liberar meus dados médicos ao patrocinador e autoridades locais.

Ao assinar este consentimento, não terei nenhum direito legal pela minha participação neste estudo,

Assinatura do paciente

Data

Assinatura de testemunha Data

Assinatura do Médico

Data

I




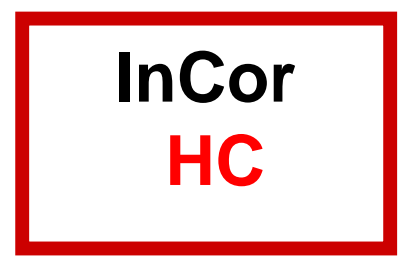

\section{TERMO DE CONSENTIMENTO LIVRE E ESCLARECIDO}

Eu, abaixo assinado, no pleno uso e gozo de minhas faculdades mentais, declaro que:

1. Sou portador(a) de Doença Arterial Coronária, conforme acabo de ser informado(a) pelo(a) meu(minha), médico(a), Dr.(a) ....................................................................., e para 0 que se oferece, dentre outros métodos existentes, opções terapêuticas para doença arterial coronária através do tratamento clínico, angioplastia ou cirurgia de revascularização miocárdica.

2. Fui informado de que estas opções terapêuticas estão sendo praticadas em vários países do mundo, inclusive na República Federativa do Brasil.

3. Segundo o meu(minha) médico(a), estas opções terapêuticas tem benefício real sobre minha doença não se estabelecendo, todavia, qual a melhor opção para minha doença e conforme dados de literatura médica especializada, outros casos semelhantes obtiveram eficácia satisfatória com qualquer uma das opções.

4. Estou ciente de que serei devidamente informado(a) sobre todos e quaisquer riscos que venham a ser identificados no futuro e aos quais possa estar exposto.

5. Tenho pleno conhecimento de que não me será paga nenhuma compensação financeira em razão de minha participação neste estudo.

6. Tenho pleno conhecimento de que meu(minha) médico(a) será responsável pelo acompanhamento do tratamento, colocando-se inteiramente à minha disposição para prestar todas e quaisquer informações a este relativas, e que venham a ser por mim solicitadas.

7. Tenho plena liberdade de desistir do tratamento a qualquer instante, sem ônus de qualquer natureza, inclusive sem prejuízo de assistência médica integral.

8. Tenho pleno conhecimento de que meu(minha) médico(a) responsável, a seu critério exclusivo, poderá incluir-me ou excluir-me do tratamento, ainda que sem meu consentimento, se decidir que assim seria mais conveniente para o restabelecimento de minha saúde ou por qualquer outro motivo, inclusive inobservância do tratamento receitado.

9. Tenho pleno conhecimento de que todos os dados obtidos em razão do presente tratamento estarão disponíveis para uso do MASS (The Medicine, Angioplasty and Surgery Study), ou do Ministério da Saúde. 
10. Recebi plenas garantias de que será mantido absoluto sigilo a respeito de minha identificação pessoal, bem como dos resultados dos registros hospitalares e de testes laboratoriais, podendo, no entanto, ser publicados, desde que minha identidade não seja revelada.

Considerando plenamente satisfatórias todas as informações prestadas, bem como as respostas às dúvidas por mim suscitadas, voluntariamente aceito este tratamento, assinando o presente Termo de Consentimento Livre e Esclarecido, juntamente com as testemunhas abaixo assinadas.

São Paulo, de de

Paciente (ou seu representante legal)
R.G. $\mathrm{n}^{\circ}$
C.I.C. $\mathrm{n}^{\mathbf{0}}$

Testemunhas:

1.

2.

(Aprovado nos termos da Resolução $\mathrm{n} \cong 196$, de outubro de 1996, Conselho Nacional de Saúde). 